\title{
Transforming Growth Factor- $\beta$ and the Renin-Angiotensin System in Syndromic Thoracic Aortic Aneurysms: Implications for Treatment
}

\author{
Daan C.H. van Dorst ${ }^{1,2}$ • Nathalie P. de Wagenaar ${ }^{3,4}$ • Ingrid van der Pluijm ${ }^{3,5}$ • Jolien W. Roos-Hesselink ${ }^{4}$. \\ Jeroen Essers ${ }^{3,5,6}$ - A.H. Jan Danser ${ }^{1}$
}

Accepted: 18 November 2020 / Published online: 7 December 2020

(C) The Author(s) 2020

\begin{abstract}
Thoracic aortic aneurysms (TAAs) are permanent pathological dilatations of the thoracic aorta, which can lead to life-threatening complications, such as aortic dissection and rupture. TAAs frequently occur in a syndromic form in individuals with an underlying genetic predisposition, such as Marfan syndrome (MFS) and Loeys-Dietz syndrome (LDS). Increasing evidence supports an important role for transforming growth factor- $\beta$ (TGF- $\beta$ ) and the renin-angiotensin system (RAS) in TAA pathology. Eventually, most patients with syndromic TAAs require surgical intervention, as the ability of present medical treatment to attenuate aneurysm growth is limited. Therefore, more effective medical treatment options are urgently needed. Numerous clinical trials investigated the therapeutic potential of angiotensin receptor blockers (ARBs) and $\beta$-blockers in patients suffering from syndromic TAAs. This review highlights the contribution of TGF- $\beta$ signaling, RAS, and impaired mechanosensing abilities of aortic VSMCs in TAA formation. Furthermore, it critically discusses the most recent clinical evidence regarding the possible therapeutic benefit of ARBs and $\beta$-blockers in syndromic TAA patients and provides future research perspectives and therapeutic implications.
\end{abstract}

Keywords Thoracic aortic aneurysm $\cdot$ Transforming growth factor- $\beta \cdot$ Renin-angiotensin system $\cdot$ Angiotensin receptorblockers . Marfan syndrome $\cdot$ Loeys-Dietz syndrome

$\overline{\text { Daan C.H. van Dorst and Nathalie P. de Wagenaar contributed equally to }}$ this work.

Jeroen Essers

j.essers@erasmusmc.nl

1 Division of Vascular Medicine and Pharmacology, Department of Internal Medicine, Erasmus University Medical Center, Rotterdam, The Netherlands

2 Department of Medical Oncology, Erasmus MC Cancer Institute, Erasmus University Medical Center, Rotterdam, The Netherlands

3 Department of Molecular Genetics, Erasmus University Medical Center, Room Ee702b, Erasmus MC, Wytemaweg 80, 3015 CN Rotterdam, The Netherlands

4 Department of Cardiology, Thoraxcenter, Erasmus University Medical Center, Rotterdam, The Netherlands

5 Department of Vascular Surgery, Erasmus University Medical Center, Rotterdam, The Netherlands

6 Department of Radiation Oncology, Erasmus University Medical Center, Rotterdam, The Netherlands

\section{Introduction: Thoracic Aortic Aneurysms}

Thoracic aortic aneurysms (TAAs) are permanent pathologic dilatations of the thoracic aorta leading to an increase of more than $50 \%$ of the normal aortic diameter [1]. Although expansion of the aneurysm is asymptomatic, TAAs can suddenly lead to life-threatening complications, such as aortic dissection and aortic rupture [2]. In most TAAs, the risk of these possibly fatal events is directly proportional to the size of the aneurysm [3,4]. Therefore, aneurysm diameter is strictly monitored in affected patients and medical therapy is initiated in an attempt to slow down TAA expansion. Most often, $\beta$ adrenergic blockers ( $\beta$-blockers) are prescribed to decrease blood pressure, cardiac contractility and shear stress on the aorta, however at variable efficacy [5]. If the aneurysm diameter exceeds certain dimensions, timely prophylactic surgical or endovascular intervention is necessary. Generally, an aneurysm diameter between 50 and $55 \mathrm{~mm}$ is regarded as indication for intervention; however, some patients require surgery at smaller diameters depending on underlying conditions and hereditary factors [5]. Several risk factors for the development 
of TAAs have been identified, such as smoking and hypertension [1].

Although the majority of TAAs are sporadic, approximately $20 \%$ of TAAs occur in a syndromic or familial form in individuals with an underlying genetic predisposition [6, 7]. The most notable of these TAA syndromes are Marfan syndrome (MFS) and Loeys-Dietz syndrome (LDS), in which TAAs will develop in a high proportion of the affected individuals $[8,9]$. Over the past 2 decades, both preclinical and clinical studies identified pathophysiological mechanisms that lead to TAAs, particularly in MFS patients. Substantial evidence demonstrates that increased signaling of the transforming growth factor- $\beta$ (TGF- $\beta$ ) pathway plays an important role in thoracic aortic pathology $[10,11]$. Nonetheless, the exact contribution of TGF- $\beta$ signaling to TAA pathogenesis remains subject of debate $[10,12]$. Additionally, the renin-angiotensin system (RAS) interacts with TGF- $\beta$ signaling on multiple levels [13] and is also shown to constitute an important contributor to TAA formation [14, 15]. More recently, impairments in cellular responses to progressive hemodynamic aortic load (mechanosensing and mechanotransduction) in syndromic individuals have been put forward to predispose to hereditary TAAs $[16,17]$. Multiple studies have investigated the therapeutic potential of compounds that inhibit TGF- $\beta$ signaling or the RAS-TGF- $\beta$ interaction in the context of TAAs, such as TGF- $\beta$ neutralizing antibodies or angiotensin receptor blockers (ARBs). This review focuses on the role of TGF- $\beta$ signaling and its interactions with RAS in syndromic TAA formation. Subsequently, the most recent clinical evidence concerning the usage of $\mathrm{ARBs}$ and $\beta$-blockers to attenuate aneurysm expansion is highlighted and critically discussed. Finally, future research perspectives and clinical implications are provided for affected TAA patients.

\section{The TGF- $\beta$ Signaling Pathway and Its Role in TAA Development}

TGF- $\beta$ signaling plays a critical role in multiple biological processes, including cellular growth, differentiation, apoptosis, migration and extracellular matrix (ECM) production [18]. Three homologous TGF- $\beta$ isoforms exist (TGF- $\beta 1$, TGF- $\beta 2$, and TGF- $\beta 3$ ), which are produced by multiple cell types as precursor proteins [19]. Increasing evidence suggests different physiological roles of these isoforms and mutations in TGF- $\beta 2$ and TGF- $\beta 3$ have been associated with TAA formation [20-23]. However, most studies in the context of thoracic aortic pathology did not discriminate between these three isoforms and this review will therefore refer to these isoforms collectively as "TGF- $\beta$ ", unless stated otherwise. After intracellular cleavage, TGF- $\beta$ remains associated with the cleaved part, the latency-associated peptide (LAP), through non-covalent interaction. Together they constitute the small latent complex (SLC). In turn, the latent TGF- $\beta$ binding protein (LTBP) interacts with LAP to form a large latent complex (LLC) before being secreted by the cell [24]. After secretion, LTBPs interact with several constituents of the ECM, including fibrillin microfibrils [25]. In this way, TGF- $\beta$ is sequestered in the ECM, which serves as an important TGF- $\beta$ reservoir. Originally, fibrillin-1 was described as a structural component of the ECM [26], but more recently it was found that fibrillin-1 can also regulate the bioavailability of TGF- $\beta 1$ by displacing the latency complex from microfibrils [27]. Besides, matrix metalloproteinases (MMPs), integrin presentation, reactive oxygen species, and thrombospondin-1 are involved in regulating release from the LLC [28-33].

After its release and activation, TGF- $\beta$ causes assembly of the TGF- $\beta$ receptor complex, which consists of two TGF- $\beta$ receptors I (TGFBR 1 ) and two TGF- $\beta$ receptors II (TGFBR2). Binding of active TGF- $\beta$ to TGFBR2 recruits TGFBR1, which becomes activated through phosphorylation by the constitutively active TGFBR2-kinase domain. Subsequently, this signal is propagated to downstream intracellular signaling cascades, which can be divided into one canonical and multiple non-canonical pathways [34-36] (Fig. 1). Interestingly, both canonical and non-canonical signaling pathways have been shown to be involved in TAA development [37-40].

\section{Canonical TGF- $\beta$ Pathway}

The canonical TGF- $\beta$ pathway is also known as the SMAD (Small Mothers Against Decapentaplegic)-dependent TGF- $\beta$ pathway, in which the activated TGF- $\beta$ receptor phosphorylates SMAD2 and SMAD3, the so-called receptor-regulated SMADs or R-SMADs (Fig. 1). Once phosphorylated, the R-SMADs have a high affinity to form a heterotrimeric complex with SMAD4 or co-SMAD. These SMAD complexes translocate to the nucleus where they interact with promotors/co-factors to regulate the transcription of downstream target genes [41-46]. These target genes are involved in the regulation of numerous processes, including ECM turnover, apoptosis and cellular proliferation, differentiation, motility and adhesion [10, 47]. Two inhibitory SMADs (I-SMADs), SMAD6 and SMAD7, are part of a negative feedback loop to regulate TGF- $\beta$ signaling (Fig. 1). Both I-SMADs can inhibit TGF- $\beta$ signaling and bone morphogenetic protein (BMP) signaling, although the effect of SMAD6 is modest $[48,49]$. Increased TGF- $\beta$ signaling correlates with increased expression of these ISMADs, suggesting that their transcription is regulated downstream of the TGF- $\beta$ pathway [50-52]. In addition, the SKI oncogene (SKI) protein inhibits the TGF- $\beta$ pathway by repression of SMAD protein activity (Fig. 1) [53]. 
Fig. 1 Overview of the TGF- $\beta$ signaling pathway. After cellular secretion, TGF- $\beta$ is sequestered in the ECM as the large latent complex (LLC). Upon release from the LLC, TGF- $\beta$ binds, assembles, and activates the TGF- $\beta$ receptor. Activation of this receptor complex initiates canonical and multiple non-canonical TGF$\beta$ signaling pathways. From left to right the canonical pathway, ERK1/2 pathway, JNK/p38 pathway, PI3K/Akt pathway, and small GTPase pathway

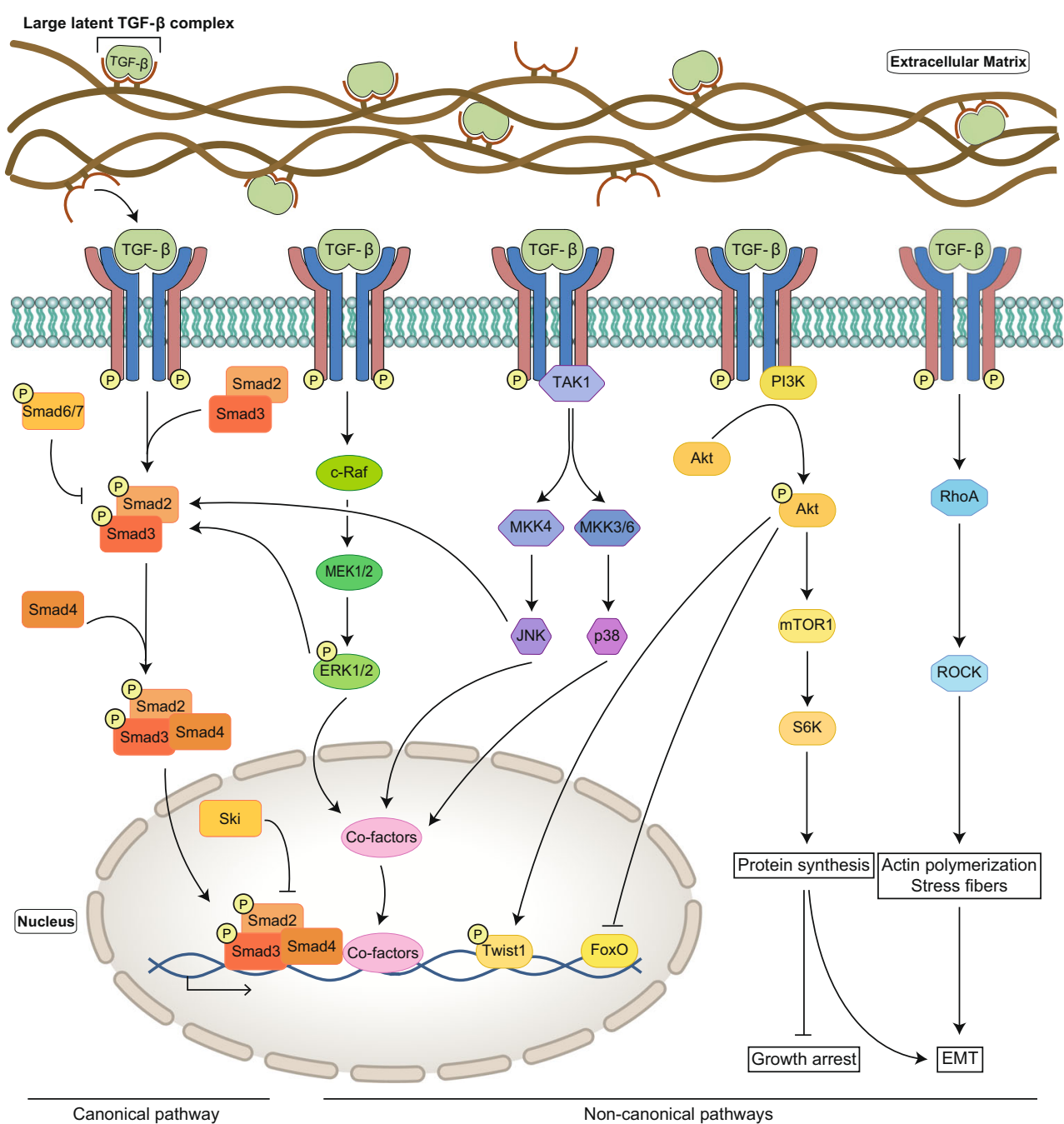

\section{Non-canonical TGF- $\beta$ Pathways}

TGF- $\beta$ signaling additionally acts via four non-canonical (SMAD-independent) pathways: ERK $1 / 2, \mathrm{JNK} / \mathrm{p} 38$, PI3K/Akt, and small GTPase [54] (Fig. 1). The first three of these pathways result in the activation of transcription factors that regulate apoptosis and epithelial-to-mesenchymal transition (EMT), often in concert with SMADs [54]. During EMT, epithelial cells differentiate into mesenchymal cells through the loss of polarity and cell-cell adhesions and acquire the capability to migrate, proliferate and differentiate. Although mesenchymal cells play a key role in tissue repair, they can also induce pathology by stimulation of tissue fibrosis [55]. Pathological EMT is predominantly associated with tumor metastasis, but this process also affects the integrity of the aortic ECM by promoting fibrosis and expression of MMPs, possibly contributing to TAA formation $[36,46]$. The small GTPase pathway is involved in dissolution of tight junctions and cell adhesion. Furthermore, it stimulates the formation of membrane protrusion and induces, via Ras homology family member A (RhoA), actin polymerization and stress fiber formation. This again affects EMT in concert with SMAD signaling, as SMAD also stimulates RhoA [54].

\section{Crosstalk of Canonical TGF- $\beta$ Pathway and Non- canonical TGF- $\beta$ Pathways}

Multiple modes of crosstalk between canonical and noncanonical TGF- $\beta$ signaling can be distinguished. Both ERK1/2 and JNK are capable of phosphorylating R-SMADs to alter their activities, and the PI3K/Akt pathway can directly influence the net outcome of SMAD signaling [40, 54]. In turn, inhibitory SMADs have been demonstrated to regulate ERK and JNK/p38 signaling [56]. In this way, complex interactions are established, and their net outcomes are often highly dependent on the cellular context in which they occur. Next to direct interactions, another important crosstalk between canonical and non-canonical TGF- $\beta$ signaling occurs at the level of DNA transcription. An example concerns the Smad3/4 complex and ERK, which have been shown to act as essential 
synergistic co-modulators of transcription of multiple TGF- $\beta$ target genes. The extensive connections between the canonical and non-canonical TGF- $\beta$ signaling pathways and the processes that are regulated by their crosstalk are reviewed in more detail elsewhere [56].

\section{TGF- $\beta$ Pathway Genes Associated with Aneurysm Formation}

TAAs are associated with a wide range of genetic mutations, which can broadly be classified into 3 main groups: genes encoding ECM constituents, genes involved in the contractile apparatus of vascular smooth muscle cells (VSMCs) and genes involved in the TGF- $\beta$ pathway [57]. Table 1 gives an overview of important genetic defects leading to TAA formation and associated syndromes and phenotypes.
The most notable in the first group are mutations in the $F B N 1$ gene, encoding the fibrillin-1 protein. Mutations in FBN1 cause MFS, an autosomal dominant connective tissue disorder [58-60]. As fibrillin-1 is a principal component of the extracellular microfibrils, abnormal or deficient production of this protein distorts structural integrity of the ECM [61]. Besides, FBN1 mutations are demonstrated to hamper TGF- $\beta$ sequestration in the ECM, which leads to enhanced TGF- $\beta$ bioavailability and increased activation of TGF- $\beta$ signaling [27, 62]. Clinically, MFS is characterized by aortic aneurysms mainly located at the level of the aortic root and multiple cardiovascular, skeletal, and ocular manifestations, such as prolapse of the atrioventricular valves, anterior chest deformity, arachnodactyly, myopia, and ectopia lentis $[8,58$, 59]. Importantly, aortic dissections occur in up to $70 \%$ of MFS patients and constitute the main cause of premature death [63].

Table 1 Genetic defects causing aortic aneurysms in human

\begin{tabular}{|c|c|c|c|c|c|}
\hline Gene & Protein & $\begin{array}{l}\text { Chromosomal } \\
\text { locus }\end{array}$ & Disease & Main clinical features & Reference \\
\hline FBN1 & Fibrillin-1 & $15 \mathrm{q} 21.1$ & Marfan syndrome & $\begin{array}{l}\text { Aortic root aneurysm and dissection, ectopia lentis, } \\
\text { myopia, pectus deformity, arachnodactyly }\end{array}$ & {$[58,59]$} \\
\hline$B G N$ & Biglycan & $\mathrm{Xq} 28$ & Meester-Loeys syndrome & $\begin{array}{l}\text { Early-onset aortic aneurysm and dissection, } \\
\text { hypertelorism, pectus deformity, joint } \\
\text { hypermobility, contractures, mild skeletal } \\
\text { dysplasia }\end{array}$ & {$[64]$} \\
\hline EFEMP2 & $\begin{array}{l}\text { EGF-containing } \\
\text { fibulin-like } \\
\text { extracellular matrix } \\
\text { protein } 2\end{array}$ & $11 \mathrm{q} 13.1$ & Cutis laxa type 1B & $\begin{array}{l}\text { Multiple arterial aneurysms and tortuosity, cutis laxa, } \\
\text { joint laxity, arachnodactyly }\end{array}$ & {$[66,67]$} \\
\hline TGFBRI & $\begin{array}{l}\text { TGF-beta receptor } \\
\text { type-1 }\end{array}$ & $9 \mathrm{q} 22.33$ & Loeys-Dietz syndrome type I & $\begin{array}{l}\text { Widespread and aggressive arterial aneurysms and } \\
\text { dissections, arterial tortuosity, hypertelorism, cleft } \\
\text { palate, bifid uvula, pectus deformity, scoliosis }\end{array}$ & {$[68]$} \\
\hline$T G F B R 2$ & $\begin{array}{l}\text { TGF-beta receptor } \\
\text { type-2 }\end{array}$ & $3 \mathrm{p} 24.1$ & $\begin{array}{l}\text { Loeys-Dietz syndrome type } \\
\text { II }\end{array}$ & $\begin{array}{l}\text { Widespread and aggressive arterial aneurysms and } \\
\text { dissections, arterial tortuosity, hypertelorism, cleft } \\
\text { palate, bifid uvula, pectus deformity, scoliosis }\end{array}$ & {$[68]$} \\
\hline SMAD3 & $\begin{array}{l}\text { Small mothers against } \\
\text { decapentaplegic } \\
\text { homolog } 3\end{array}$ & $15 q 22.33$ & $\begin{array}{l}\text { Loeys-Dietz syndrome type } \\
\text { III (also known as } \\
\text { aneurysm-osteoarthritis } \\
\text { syndrome) }\end{array}$ & $\begin{array}{l}\text { Widespread and aggressive arterial aneurysms and } \\
\text { dissections, arterial tortuosity, early-onset } \\
\text { osteoarthritis, osteochondritis dissecans, } \\
\text { hypertelorism, bifid uvula }\end{array}$ & {$[69,70]$} \\
\hline TGFB2 & $\begin{array}{l}\text { Transforming growth } \\
\text { factor beta-2 }\end{array}$ & $1 \mathrm{q} 41$ & $\begin{array}{l}\text { Loeys-Dietz syndrome type } \\
\text { IV }\end{array}$ & $\begin{array}{l}\text { Thoracic aortic aneurysm and dissection, arterial } \\
\text { tortuosity, mitral valve prolapse, arachnodactyly, } \\
\text { flat feet, high arched palate, joint hyperflexibility }\end{array}$ & {$[21]$} \\
\hline TGFB3 & $\begin{array}{l}\text { Transforming growth } \\
\text { factor beta-3 }\end{array}$ & $14 \mathrm{q} 24.3$ & $\begin{array}{l}\text { Loeys-Dietz syndrome type } \\
\text { V }\end{array}$ & $\begin{array}{l}\text { Aortic aneurysm and dissection, mitral valve } \\
\text { prolapse, hypertelorism, arachnodactyly, cleft } \\
\text { palate, bifid uvula, pectus deformity, scoliosis }\end{array}$ & {$[22]$} \\
\hline SMAD2 & $\begin{array}{l}\text { Small mothers against } \\
\text { decapentaplegic } \\
\text { homolog } 2\end{array}$ & $18 \mathrm{q} 21.1$ & $\begin{array}{l}\text { Loeys-Dietz syndrome type } \\
\text { VI }\end{array}$ & $\begin{array}{l}\text { Arterial aneurysms and dissections, valve } \\
\text { abnormalities, hypertelorism, pectus deformity, } \\
\text { scoliosis, osteoarthritis, hernias }\end{array}$ & {$[71,72]$} \\
\hline SMAD4 & $\begin{array}{l}\text { Small mothers against } \\
\text { decapentaplegic } \\
\text { homolog } 4\end{array}$ & $18 \mathrm{q} 21.2$ & Haemorrhagic telangiectasia & $\begin{array}{l}\text { Gastrointestinal hamartomatous polyps, cutaneous } \\
\text { and mucosal telangiectasia, epistaxis, } \\
\text { arteriovenous malformations }\end{array}$ & {$[77]$} \\
\hline SMAD6 & $\begin{array}{l}\text { Small mothers against } \\
\text { decapentaplegic } \\
\text { homolog } 6\end{array}$ & $15 \mathrm{q} 22.31$ & $\begin{array}{l}\text { Bicuspid aortic } \\
\text { valve/thoracic aortic an- } \\
\text { eurysm }\end{array}$ & Bicuspid aortic valve, thoracic aortic aneurysm & {$[80]$} \\
\hline$S K I$ & Ski oncogene & 1p36.33-p36.32 & $\begin{array}{l}\text { Shprintzen-Goldberg } \\
\text { syndrome }\end{array}$ & $\begin{array}{l}\text { Craniosynostosis, hypertelorism, high palate, } \\
\text { micrognathia, arachnodactyly, joint contractures, } \\
\text { pectus deformity, hypotonia, developmental delay }\end{array}$ & {$[78,79]$} \\
\hline
\end{tabular}


Another prominent example of this first group of mutations are mutations in $B G N$, encoding biglycan, a small proteoglycan involved in assembly and maintenance of the ECM which is known to interact with TGF- $\beta$ [64]. Lack of functional biglycan results in increased TGF- $\beta$ bioavailability, mainly in the vascular adventitia layer which is the major site of biglycan deposition [65]. Patients with $B G N$ mutations are characterized by early-onset aortic aneurysms and aortic dissections, hypertelorism, pectus deformity, joint hypermobility, contractures, and mild skeletal dysplasia [64]. Lastly, mutations in EFEMP2 lead to impaired function of the EGFcontaining fibulin-like extracellular matrix protein 2 , better known as fibulin-4. Fibulin-4 interacts with multiple ECM components and is involved in elastogenesis, cross-linking, and regulation of TGF- $\beta$ activity. Fibulin- 4 mutations cause cutis laxa type $1 \mathrm{~B}$, which is a syndromic autosomal recessive condition characterized by aortic aneurysms, non-elastic loose skin (cutis laxa), vascular deformities, aneurysms, joint laxity and arachnodactyly [66, 67].

Examples of mutations in contractile apparatus genes leading to TAA are smooth muscle cell-specific isoforms of $\alpha$ actin (ACTA2) and myosin heavy chain (MYH1 1). Mutations in these genes result in non-syndromic TAA and are reviewed elsewhere [16].

This review particularly focuses on genetic mutations affecting the TGF- $\beta$ pathway that lead to TAA formation. In the past 2 decades, numerous mutations in genes encoding proteins of the TGF- $\beta$ pathway were discovered to be associated with aneurysm formation. Notably, different mutations in the TGF- $\beta$ pathway cause LDS, an autosomal dominant connective tissue disorder. LDS can be classified into six different subtypes, according to the underlying mutation (TGFBR1, TGFBR2, SMAD3, TGFB2, TGFB3, and SMAD2) [21, 22, 68-73]. LDS patients share many phenotypical characteristics with MFS patients, but LDS vascular pathology is often more aggressive and more widespread, affecting the entire arterial tree. This includes widespread arterial tortuosity and aneurysms of various medium-to-large muscular arteries, including the aorta and cerebral arteries [74]. Importantly, aortic aneurysms tend to dissect at smaller diameters and at a younger age $[74,75]$ and a high proportion of the affected individuals eventually require surgical intervention [76]. In addition, mutations in SMAD4 and in $S K I$, an inhibitor of the TGF- $\beta$ pathway, cause hemorrhagic telangiectasia and Shprintzen-Goldberg syndrome respectively. Both conditions are associated with thoracic aortic pathology, although this is less common than in MFS and LDS [77-79]. Besides, mutations in SMAD6, another inhibitor of TGF- $\beta$ signaling, are associated with bicuspid aortic valve and TAA [80]. Altogether this highlights the essential role of the TGF- $\beta$ pathway in cardiovascular diseases, particularly, but not limited to, the formation of TAAs.

\section{Mouse Models for TAA}

The identification of genes responsible for heritable TAAs enabled the generation of mouse models with a TAA phenotype (Table 2). Of note, the exact TAA phenotypes vary considerably, due to differences in genetic background. Nonetheless, these mouse models allowed not only a more in-depth analysis of the effects of these different genetic mutations but also an evaluation of different potential treatment modalities targeting aneurysm growth.

Firstly, several mouse models for MFS exist, harboring mutations in Fbnl. Fbn $1^{\mathrm{mgN} / \mathrm{mgN}}$ and $F b n 1^{G T-8 / G T-8}$ mice lack $F b n 1$ expression, $F b n 1^{m g \Delta / m g \Delta}$ mice have 10 -fold reduced $F b n 1$ expression and $F b n I^{m g R / m g R}$ have 4- to 5 -fold reduced Fbnl expression [81-84]. Finally, Fbn1 ${ }^{C 1041 G /+}$ mice mimic a patient missense mutation $(\mathrm{C1039}$ Y), which results in reduced formation of fibrillin-1 fibers, despite normal $F b n 1$ expression [85]. Of note, Fbn $1^{m g N / m g N}, F b n 1^{G T-8 / G T-8}$ mice, and $F b n 1^{m g \Delta / m g \Delta}$ mice die in the first weeks of life, whereas homozygous $F b n 1^{m g R / m g R}$ mice die around 4-6 months due to aortic dissections [81-84]. Although MFS patients nowadays have near-normal lifespan [86], the average life expectancy for MFS patients in 1972, before the evolution of open-heart surgery, was reported to be 32 years and most patients died due to aortic dissections [87, 88]. This phenotype is mostly phenocopied by untreated $F b n I^{m g R / m g R}$ mice. In contrast, $F b n 1^{C 1041 G /+}$ mice have a normal life span [85]. This could imply that lower expression of Fbn1 results in a more severe phenotype.

Secondly, several mouse models for LDS have been established. Full knock-out models for $T g f b r 1, T g f b r 2$ and Smad3 were generated, as well as mice with a conditional knock-out of $T g f b r l$ and $T g f b r 2$ specifically in the endothelium, VSMCs or neural crest [39, 89-95]. In addition, a mouse model with a postnatal SMC-specific Tgfbr2 deletion and $T g f b r 1^{M 318 R /+}$ and $T g f b r 2^{G 257 W /+}$ mouse models with heterozygous kinase-inactivating missense mutations were created [96-98]. Smad3 knock-out mice develop aneurysms and histological analysis of TAA tissue reveal fragmentation of the elastic laminae and aortic immune infiltration, similar to the alterations observed in the human situation [39, 89]. Conventional knock-outs for $T g f b r l$ or $T g f b r 2$ and conditional knock-outs for $T g f b r 1$ or $T g f b r 2$ in endothelial cells or VSMCs are embryonic lethal, due to serious defects in vascular development [90-92]. Conditional knock-out of $T g f b r l$ or $T g f b r 2$ is lethal during birth or in the immediate postnatal period [93-95]. Postnatal SMC-specific Tgfbr2 deletion results in vascular abnormalities, which are also found in LDS patients [98]. $\mathrm{Tg} f b r 1^{\mathrm{M} 318 R /+}$ and $\mathrm{Tg} f b r 2^{G 257 W / 4}$ mice have cardiovascular and craniofacial abnormalities, partly overlapping with the characteristics of LDS patients [96, 97].

Thirdly, several mouse models harboring mutations in $F b l n 4$, encoding fibulin-4, have been created. As mentioned, 
Table 2 Genetic mouse models for thoracic aortic aneurysms

\begin{tabular}{|c|c|c|c|c|}
\hline Gene & Mouse model & Expression & Phenotype & References \\
\hline \multirow[t]{5}{*}{ Fbnl } & $F b n 1^{m g N / m g N}$ & No Fbnl expression & $\begin{array}{l}\text { Postnatal death within } 2 \text { weeks due to ruptured aortic aneurysm, } \\
\text { impaired pulmonary function, and/or diaphragmatic collapse, } \\
\text { aneurysms mainly located in the ascending aorta }\end{array}$ & {$[81]$} \\
\hline & $F b n l^{m g \Delta / m g \Delta}$ & $\begin{array}{l}\text { 10-fold reduced } F b n l \\
\text { expression }\end{array}$ & $\begin{array}{l}\text { Postnatal death within } 3 \text { weeks of age due to cardiovascular } \\
\text { complications }\end{array}$ & {$[82]$} \\
\hline & $F b n 1^{G T-8 / G T-8}$ & $\begin{array}{l}\text { No significant } F b n 1 \\
\text { expression }\end{array}$ & Postnatal death within 3 weeks of age & {$[83]$} \\
\hline & $F b n 1^{m g R / m g R}$ & $\begin{array}{l}\text { 4- to } 5 \text {-fold reduced } F b n 1 \\
\text { expression }\end{array}$ & $\begin{array}{l}\text { Average lifespan of } 4 \text { months, aneurysm formation and } \\
\text { dissection/rupture, pulmonary insufficiency }\end{array}$ & {$[84]$} \\
\hline & $\mathrm{Fbn1} \mathrm{Cl}^{\mathrm{C1041G/+}}$ & $\begin{array}{l}\text { Missense mutation, normal } \\
\text { expression }\end{array}$ & Normal lifespan, aortic aneurysm formation & [85] \\
\hline Smad3 & Smad $3^{-/-}$ & No Smad3 expression & $\begin{array}{l}\text { Sudden death between } 6 \text { and } 30 \text { weeks of age due to thoracic } \\
\text { aneurysmal dissection or cardiac tamponade, aneurysm } \\
\text { formation in aorta and other vessels, increased aortic length, } \\
\text { fragmentation of the elastic laminae, immune cell filtration }\end{array}$ & {$[39,89]$} \\
\hline \multirow[t]{3}{*}{ Tgfbrl } & $T g f b r l$ knock-out & No Tgfbrl expression & Embryonically lethal, severe defects in vascular development & {$[92]$} \\
\hline & $\begin{array}{l}T g f b r l \text { conditional knock-out } \\
\text { (endothelium, VSMCs and } \\
\text { neural crest) }\end{array}$ & $\begin{array}{l}\text { No } T g f b r l \text { expression in } \\
\text { specific cell types }\end{array}$ & $\begin{array}{l}\text { Endothelium and VSMC specific: embryonically lethal, severe } \\
\text { defects in vascular development } \\
\text { Neural crest specific: lethal during birth or postnatal-hours, severe } \\
\text { cardiovascular and pharyngeal defects }\end{array}$ & {$[90,93]$} \\
\hline & $\operatorname{Tg} f b r 1^{M 318 R / 4}$ & $\begin{array}{l}\text { Missense mutation, normal } \\
\text { expression }\end{array}$ & $\begin{array}{l}\text { Predisposition to aortic dissection and early death, aortic root } \\
\text { aneurysm, tortuosity, elastic fiber fragmentation, craniofacial } \\
\text { and skeletal abnormalities }\end{array}$ & {$[96,97]$} \\
\hline \multirow[t]{4}{*}{ Tgfbr2 } & $T g f b r 2$ knock-out & No $T g f b r 2$ expression & Embryonically lethal, severe defects in vascular development & [91] \\
\hline & $\begin{array}{l}T g f b r 2 \text { conditional knock-out } \\
\text { (endothelium, VSMCs and } \\
\text { neural crest) }\end{array}$ & $\begin{array}{l}\text { No } T g f b r 2 \text { expression in } \\
\text { specific cell types }\end{array}$ & $\begin{array}{l}\text { Endothelium and VSMC specific: embryonically lethal, severe } \\
\text { defects in vascular development } \\
\text { Neural crest specific: immediate postnatal death, severe cranial and } \\
\text { cardiovascular malformations }\end{array}$ & $\begin{array}{c}{[90,94,} \\
95]\end{array}$ \\
\hline & $\begin{array}{l}T g f b r 2 \text { postnatal SMC-specific } \\
\text { deletion }\end{array}$ & $\begin{array}{l}95 \% \text { reduction of } T g f b r 2 \\
\text { expression after } \\
\text { tamoxifen treatment }\end{array}$ & $\begin{array}{l}\text { Aortic dilatation, dissection, hemorrhage and ulceration, } \\
\text { elastolysis, macrophage infiltration, abnormal proteoglycan } \\
\text { accumulation }\end{array}$ & {$[98,115]$} \\
\hline & $\operatorname{Tg} f b r 2^{G 257 W /+}$ & $\begin{array}{l}\text { Missense mutation, normal } \\
\text { expression }\end{array}$ & $\begin{array}{l}\text { Predisposition to aortic dissection and early death, aortic root } \\
\text { aneurysm, tortuosity, elastic fiber fragmentation, craniofacial } \\
\text { and skeletal abnormalities }\end{array}$ & {$[97]$} \\
\hline \multirow[t]{4}{*}{ Fbln 4} & $F b \ln 4^{-1}$ & No Fbln 4 expression & $\begin{array}{l}\text { Early postnatal death, arterial tortuosity, aortic aneurysm formation } \\
\text { and rupture }\end{array}$ & [99] \\
\hline & $\mathrm{Fbln} 4^{f /-} / \mathrm{SM} 22 \mathrm{Cre}+$ & $\begin{array}{l}\text { No } F b \ln 4 \text { expression in } \\
\text { VSMCs }\end{array}$ & $\begin{array}{l}\text { Reduced lifespan, aneurysm formation, fragmentation of the elastic } \\
\text { laminae }\end{array}$ & [100-102] \\
\hline & $F b \ln 4^{R / R}$ & $\begin{array}{l}\text { 4-fold reduced } F b \ln 4 \\
\quad \text { expression }\end{array}$ & $\begin{array}{l}\text { Sudden death within first } 3 \text { weeks of life, aneurysm formation and } \\
\text { dissection }\end{array}$ & {$[103,104]$} \\
\hline & $F b \ln 4^{E 57 K / E 57 K}$ & $\begin{array}{l}\text { Missense mutation, normal } \\
\text { expression }\end{array}$ & Aneurysm formation, fragmentation of the elastic laminae & {$[67,105]$} \\
\hline
\end{tabular}

fibulin-4 plays an important role in elastic fiber formation and mutations in EFEMP2 (the human gene encoding fibulin-4) cause cutis laxa type $1 \mathrm{~b}$. Importantly, a complete knock-out of Fbln4 (Fbln $4^{-1}$ ) results in perinatal death [99]. In order to generate a more viable mouse model, a VSMC-specific knock-out (Fbln $4^{f /-} / \mathrm{SM} 22 \mathrm{Cre}+$ ) was generated, in which aneurysms in the ascending aorta develop rapidly, accompanied by fragmentation of the elastic laminae [100-102]. Besides, $F b \ln 4^{R / R}$ mice, expressing only $25 \%$ of fibulin- 4 compared to wild-type mice, present with aneurysms throughout the entire aorta, fragmentation of the elastic lamina, and increased ECM deposition. In these mice, increased upstream and downstream TGF- $\beta$ signaling was detected by elevated levels of TGF- $\beta$ ligand, increased SMAD2 phosphorylation and increased activation of the downstream target plasminogen activator inhibitor-1 (PAI-1) [103, 104]. Lastly, Fbln $4^{E 57 K / E 57 K}$ mice express a mutated form of fibulin-4, which impairs binding to LTBP1 and reduces assembly of the ECM. Similarly, this results in aneurysm formation and fragmentation of elastic laminae $[67,105]$.

\section{The Role of TGF- $\beta$ Signaling in TAA}

Over the years, dysregulation of TGF- $\beta$ signaling has been proposed in multiple TAA syndromes. Neptune et al. were the first to propose a detrimental role of TGF- $\beta$ signaling in MFS, 
as they demonstrated that mice deficient in fibrillin-1 $\left(F b n 1^{m g \Delta / m g} \Delta\right.$ ) have upregulated TGF- $\beta$ activation and signaling. This led to impaired lung development due to increased cellular apoptosis [27]. As these $F b n I^{m g \Delta / m g \Delta}$ mice die around postnatal day 12, a Fbn1 mouse model with a missense mutation $\left(\mathrm{Fbnl}^{\mathrm{Cl041G/+}}\right)$ was created to enable better analysis of aneurysm development. In this model, Habashi et al. demonstrated that increased TGF- $\beta$ signaling, based on increased pSMAD2 levels, is associated with TAA development [106]. Additional evidence for the involvement of TGF- $\beta$ signaling in TAA was the finding that mutations in TGF- $\beta$ pathway genes also predispose to TAA, such as in LDS patients (Table 1). Remarkably, most of these mutations constitute loss-of-function mutations, but yet seem to enhance TGF- $\beta$ signaling [107]. Indeed, nuclear accumulation of phosphorylated SMAD2 and SMAD3 and increased expression of TGF- $\beta$-regulated genes was found in LDS patients with TGFBR1 and TGFBR2 mutations. This is indicative of upregulated TGF- $\beta$ signaling $[68,108,109]$. Indeed, pSMAD2 activation is often used as a readout for TGF- $\beta$ activation $[22,97,106]$. Interestingly, upregulated TGF- $\beta$ signaling is also observed with mutations in the other genes that cause LDS, such as TGFB2, TGFB3, and SMAD3 [21, 22, $70]$. How this paradoxically elevated TGF- $\beta$ signaling, known as "the TGF- $\beta$ paradox", is mediated at a functional level is still not fully understood. One potential explanation for the TGF- $\beta$ paradox, observed in in $\mathrm{Smad}^{-/}$mice, is that these genetic mutations lead to increased upstream canonical TGF- $\beta$ signaling (pSMAD2), without affecting downstream canonical TGF- $\beta$ signaling [39]. In addition, mutations in $F B N 1$ and EFEMP2 were found to indirectly affect TGF- $\beta$ signaling $[103,110]$. In turn, excessive TGF- $\beta$ signaling in adult aorta has been linked to improper remodeling of the vascular ECM, VSMC dysfunction and TAA development $[111,112]$. Excessive TGF- $\beta$ signaling also leads to increased expression and activity of MMPs, degradation of elastic fibers, enhanced proliferation and migration of VSMCs and excessive secretion and deposition of collagens [111, 113]. These effects could all contribute to weakening of the aortic wall, rendering it more vulnerable for dilation, dissection and rupture [111].

Interestingly, treatment with TGF- $\beta$-neutralizing antibodies, from 7 to 15 weeks of age, normalized TGF- $\beta$ signaling in the aortic media and improved elastic fiber fragmentation and aortic wall architecture in $F b n 1^{C 1041 G / 4}$ mice. Also, this treatment reduced aortic wall thickness and attenuated growth of the aortic root [106]. This indicates that excessive TGF- $\beta$ signaling contributes to the formation of aortic aneurysms and that TGF- $\beta$ antagonism is a potential treatment strategy. Importantly, it has been shown that adequate timing of TGF- $\beta$ neutralization is essential. In $F b n I^{m g R / m g R}$ mice, a beneficial effect of TGF- $\beta$ neutralization was observed when the treatment was started after onset of aneurysm formation (8-week old mice). However, if treatment with TGF- $\beta$-neutralizing antibodies was started before onset of aneurysm formation (postnatal day 16), this led to an acceleration in aneurysm development [114]. Besides, prenatal VSMC-specific $T g f b r 2$ deletion in mice results in defective elastogenesis, vessel wall dilatation, aneurysms, and dissections [94, 115, 116]. In contrast, these harmful effects did not occur when this VSMC-specific $T g f b r 2$ deletion was induced in mice at the age of 8-weeks [115]. This indicates that TGF- $\beta$ has a protective role against aneurysm formation early in vascular development. Indeed, the TGF- $\beta$ signaling pathway has been demonstrated to play an essential role in the initial vascular formation during embryogenesis, as mice with a knock-out mutation in either $T g f b 1, T g f b r 1$, or $T g f b r 2$ developed severe defects in yolk sac vasculogenesis and hematopoiesis [117], predisposing to early embryonic lethality [90]. Also, TGF- $\beta$ signaling is important for the formation of the embryonic vascular plexus, proper elastogenesis during embryogenesis and during the first weeks of life and for the development, morphogenesis and migration of endothelial cells and VSMCs [111, 118, $119]$. Once these processes are completed, TGF- $\beta$ seems to switch to become a detrimental contributor to aortic pathology $[106,111,114]$, as reflected by the observed beneficial effects of TGF- $\beta$ neutralization in a later stage [106]. Thus, adequate timing of TGF- $\beta$ neutralization seems essential to optimally benefit from its protective effects on TAA formation, sparing the early protective role of TGF- $\beta$ signaling [114]. However, the consequences of TGF- $\beta$ neutralization on aortic pathology also seems to be dependent on the animal model studied. In a mouse model in which aortic aneurysm formation was induced by continuous administration of angiotensin II (Ang II), concomitant treatment with a TGF- $\beta$ neutralizing antibody promoted aortic rupture, mostly at the level of the ascending aorta and suprarenal aortic region. In contrast, treatment with a TGF- $\beta$ neutralizing antibody after the Ang II treatment period had no detrimental effects on aortic morphology [120]. This again stresses the variable effects of TGF- $\beta$ neutralization at different developmental timepoints.

Another observation that adds to the complexity of the exact role of TGF- $\beta$ in aneurysm formation was described by MacFarlane et al. In their study, they found that the effect of the Tgfbrl mutation, and subsequent disturbance in TGF- $\beta$ signaling in the $T g f b r 1^{M 318 R /+}$ LDS mouse model, varies between VSMCs that are derived from distinct lineages of origin. Their study suggests that the predisposition to aortic root aneurysm in LDS mice depends on both defective SMAD signaling in secondary heart field-derived VSMCs and excessive SMAD signaling in cardiac neural crest-derived VSMCs [96]. This is in line with previous findings in avian systems, which show that neural crest-and mesoderm-derived VSMCs respond differently to TGF- $\beta 1$. To be more precise, cellular proliferation and fibrosis were seen in the neural crest-derived VSMCs and growth inhibition in the mesoderm-derived 
VSMCs [106, 121, 122]. Although this concept has not been further verified in other aortic aneurysm syndromes, perturbations in TGF- $\beta$ signaling could thus have different effects on the various cell types that comprise the aortic tissue.

In summary, combinatory evidence from TAA mouse models and human genetic studies reveals a dimorphic role of TGF- $\beta$ signaling in the development of TAA. During embryogenesis and in the first weeks of life, it has protective effects, whereas at a later time point it is an important contributor to thoracic aortic pathology. Also, the exact effects of TGF- $\beta$ signaling are suggested to depend on the developmental origin of aortic VSMCs.

\section{The Renin-Angiotensin System and Its Interaction with the TGF- $\beta$ Signaling Pathway in Thoracic Aneurysm Formation}

Another system that has repeatedly been reported to play an essential role in TAAs is RAS, which is a critical regulator of blood pressure, extracellular fluid homeostasis and electrolyte balance (Fig. 2). Ang II, the principal effector of the RAS, can stimulate both the Ang II type 1 receptor (AT1R) and the Ang II type 2 receptor (AT2R), but mainly acts via the former to exert its well-known functions, such as vasoconstriction, fibrosis and inflammation $[14,15]$. Notably, infusion of Ang II leads to aneurysm formation of the abdominal aorta in apolipoprotein E-deficient mice [123, 124], but also to rapid expansion of the thoracic aorta with typical histological alterations, such as elastin fragmentation and increased medial thickness [123, 125, 126]. Additionally, increased plasma Ang II concentrations are observed in TAA patients [127, 128]. Interestingly, blockade of Ang II-AT1R signaling attenuated aortic root expansion in multiple preclinical and clinical studies [37, 106, 129, 130]. This stresses the importance of RAS in thoracic aortic pathology. Figure 3 summarizes several mechanisms by which the RAS may influence aneurysmal disease, which is discussed in more detail below.

\section{AT1R Signaling}

As stated, Ang II mainly exerts its effects via the AT1R, which could contribute to TAA formation. An important aspect is also where exactly the vascular AT1Rs relevant for signaling in TAAs are located. Unlike humans, rodents have 2 types of AT1R ( $a$ and $b$ ). VSMC-specific deletion of the most abundant subtype (AT1aR) did not affect aortic pathology in Fbn $1^{m g R / m g R}$ mice [131], nor in an ascending aortic aneurysm model (LDL receptor ${ }^{-/-}$mice fed a saturated fat diet and infused with Ang II) [132]. Thus, either the relevant AT1R are located on other vascular cells (endothelial cells and/or fibroblasts) [131-133], or continued AT1R stimulation via remaining AT1bR might occur. In case of the former, a likely

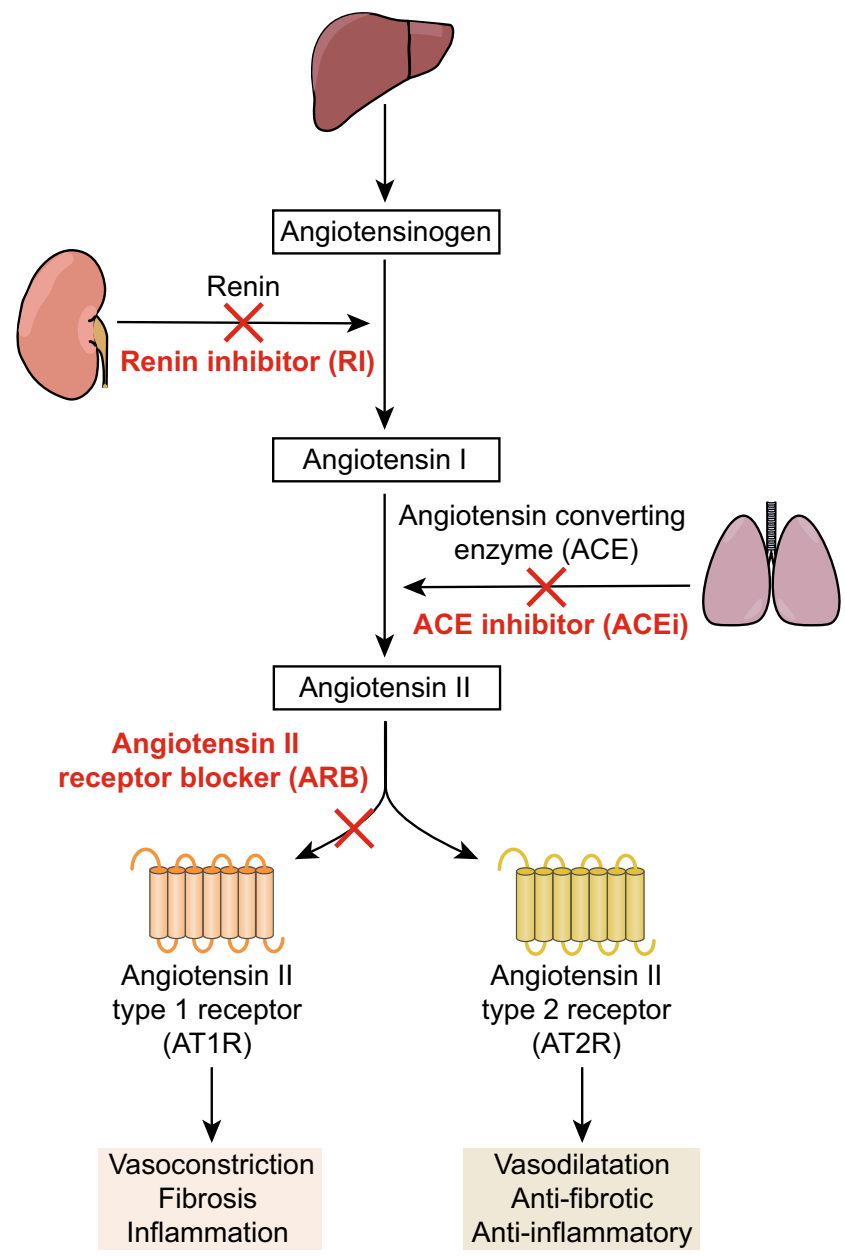

Fig. 2 The renin-angiotensin system (RAS) and RAS blocking agents. Kidney-derived renin cleaves liver-derived angiotensinogen to generate angiotensin I, which is subsequently converted by angiotensinconverting enzyme (ACE) to angiotensin II, the main effector of the RAS. Angiotensin II stimulates its type 1 and 2 receptors, resulting in opposing effects on vasoactivity, fibrosis, and inflammation $[14,15]$. RAS inhibition is possible with renin inhibitors, ACE inhibitors, and angiotensin II type 1 receptor blockers

scenario is that VSMCs are affected by factors released from other vascular cells following their stimulation by Ang II. To rule out the latter, mice lacking both AT1R subtypes in VSMCs need to be studied.

\section{AT2R Signaling}

AT2R stimulation is generally regarded to counter-regulate the effects mediated by the AT1R [15]. One of the rationales behind the therapeutic usage of ARBs is that the upregulated Ang II during RAS blockade is redirected from the blocked AT1R to the non-blocked AT2R to activate alternative transcriptional programs. This yields protection in numerous cardiovascular conditions, such as hypertension and heart failure. Yet, the exact role of the AT2R in aortic aneurysm remains 


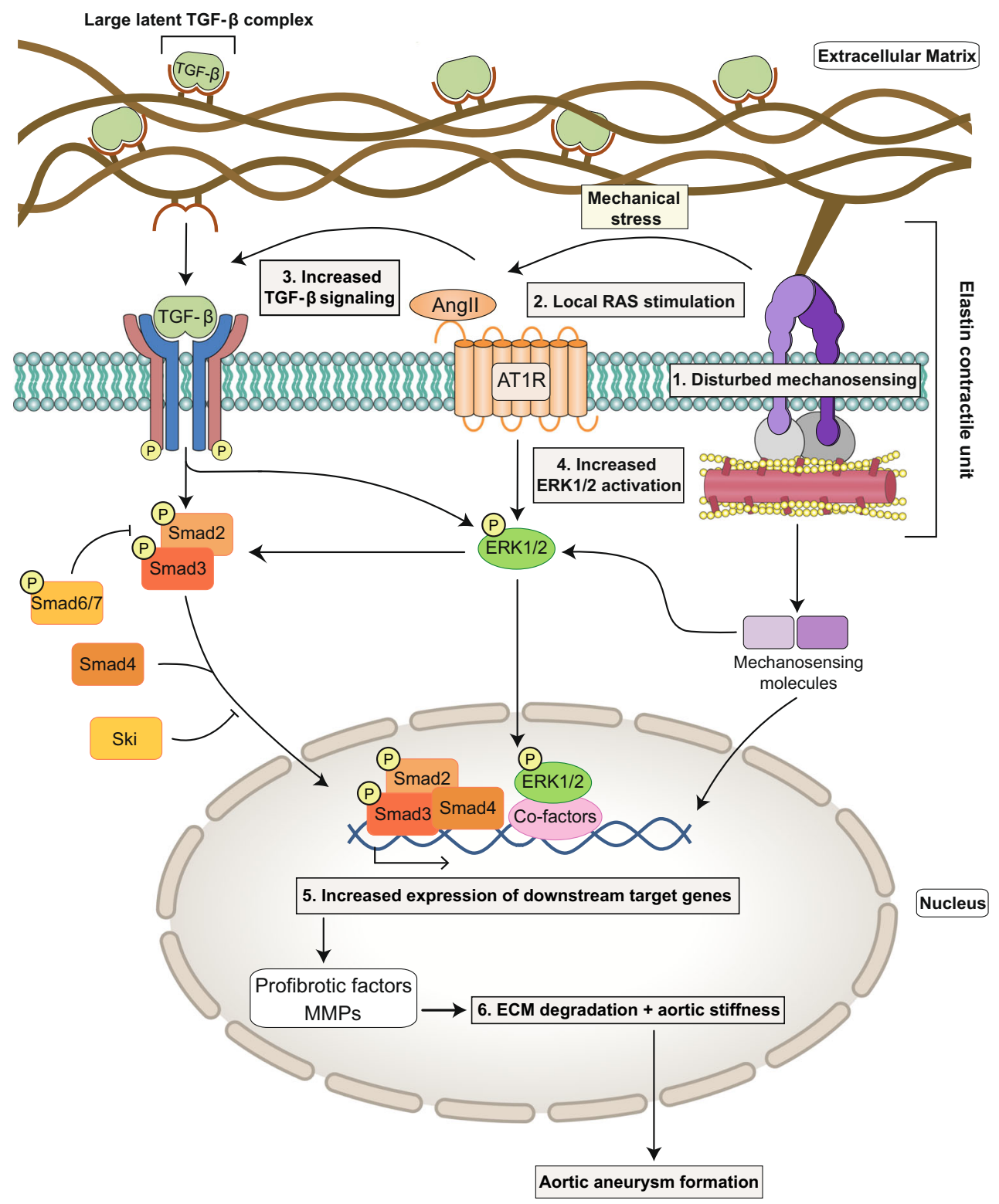

Fig. 3 Hypothesized mechanism involving TGF- $\beta$ signaling, RAS and disturbed mechanosensing abilities of aortic VSMCs that leads to TAA in syndromic individuals. Normally, TGF- $\beta$ signaling, RAS, and mechanosensing in aortic VSMCs, via elastin-contractile units, cooperate to control aortic ECM remodeling and to maintain ECM integrity. However, in the situation of syndromic aneurysmal disease involving mutations in constituents of the ECM or the elastin-contractile unit, mechanosensing abilities are disturbed (1). This leads to mechanical stress, which stimulates local RAS activity by inducing ACE expression and activating the AT1R (2). Also, alternative, less-characterized mechanisms that stimulate local RAS activity might come into play in TAA

controversial [134]. On the one hand, previous studies demonstrated that the ability of the ARB losartan to attenuate aortic enlargement required availability of AT2R signaling [135]. Also, knock-out of the AT2R gene resulted in larger aortic diameters and an increased number of premature deaths in $F b n 1^{C 1041 G / 4}$ mice [37]. As the exact causes of deaths in this study were not provided, it remains uncertain if these formation. This increased RAS signaling can act as an upstream activator of TGF- $\beta$ signaling (3) but also directly increase ERK1/2 signaling (4). In turn, TGF- $\beta$ hyperactivity induces both canonical TGF- $\beta$ signaling and non-canonical ERK1/2 signaling. Consequently, expression of target genes, among them MMPs and profibrotic factors such as connective tissue growth factor (CTGF) and PAI-1 is highly increased (5). Eventually, overexpression of these factors can lead to detrimental ECM degradation and aortic stiffness (6), which contributes to aortic aneurysm formation in affected syndromic individuals. In turn, ECM degradation leads to higher bioavailability of sequestered TGF- $\beta$, further amplifying this process

could be attributed to aortic complications, such as aortic dissection and rupture. In addition, renin inhibitors (RI) and angiotensin-converting enzyme inhibitors (ACEi), blocking both AT1R and AT2R signaling (Fig. 2), were less effective than ARBs in decreasing aortic root dilatation in $F b \ln 4^{R / R}$ [136] and Fbn ${ }^{C 1041 G /+}$ mice [37] and preventing transverse aortic constriction-induced aneurysm formation in wild-type 
mice [135]. Of note, only single dosages of these classes of drugs were investigated and other dosages might have yielded different outcomes. Nonetheless, these results advocate a protective role of the AT2R in aneurysm formation. On the other hand, a recent study demonstrated that direct AT2R stimulation with the AT2R agonist C21 did not show beneficial effects on TAAs in $F b n 1^{C 1041 G /+}$ mice [137]. In line with this, blockade of the AT2R did not accelerate Ang II-induced aneurysm growth in hypercholesterolemic mice [123]. Lastly, losartan continued to exert beneficial effects on aortic pathology after deletion of the AT2R in mice harboring a VSMC-specific knock-out of Fbln 4 [100]. This indicates that AT2R activation in combination with AT1R blockade is only essential to yield protective effects under specific genetic conditions. Of note, the animal models in these studies display wide heterogeneity and the role of the AT2R in aortic pathology could depend on the exact genetic background, the mechanism by which the aneurysm is induced and timing and duration of treatment. In the human situation, most tissues display low AT2R expression, except during embryonic development [138]. Although AT2R upregulation is reported under pathological conditions, which could include aortic diseases [139], it is also possible that AT2R signaling comes into play at a later stage of aortic aneurysm development and is not involved in its initial pathogenesis [136].

\section{Interaction with TGF- $\beta$ Signaling}

The RAS interacts with TGF- $\beta$ signaling at multiple levels and this might compose a mechanism by which it contributes to thoracic aortic pathology. Importantly, Ang II-AT1R signaling acts as an upstream activator of TGF- $\beta$ signaling: Ang II directly increases TGF- $\beta$ mRNA production, TGF- $\beta$ protein expression and TGF- $\beta$ activity $[13,140,141]$. As various TAA syndromes such as MFS and LDS are characterized by increased TGF- $\beta$ signaling, this could be secondary to elevated RAS signaling. Indeed, abnormal upregulation of ACE and subsequent elevated local Ang II-AT1R signaling has been demonstrated in mice harboring a VSMC-specific knock-out of $F b \ln 4$, leading to ascending aortic aneurysms [100]. Also, enhanced AT1R downstream responses to Ang II stimulation are observed in Fbln4-deficient VSMCs [17]. Theoretically, increased RAS signaling in the context of aortic aneurysms could also be due to increased receptor density of the AT1R. However, to the best of our knowledge, this has not been studied in human TAAs yet.

\section{Perturbed Mechanosensing}

One of the mechanisms that could lead to increased Ang IIAT1R signaling in syndromic TAAs is mechanical stress due to perturbations in mechanosensing. The aortic wall is continuously subjected to varying hemodynamic loads, such as a pulsatile blood pressure [142]. Normally, these mechanical forces are sensed by aortic VSMCs via elastin-contractile units (Fig. 3), which are composed of intracellular contractile elements linked to elastic fibers and microfibrils in the aortic ECM via focal adhesions [143]. In response to these mechanical cues, VSMCs activate downstream targets (mechanosensing molecules) which alter downstream gene expression to influence the composition of the ECM. Sensing the biomechanical environment (mechanosensing) and propagation of this signal intracellularly (mechanotransduction) to remodel the ECM under various hemodynamic circumstances are essential to ensure sufficient strength and compliance of the aortic wall and to maintain aortic wall integrity [143]. Consequently, genetic mutations in components of the elastin-contractile units, such as fibrillin-1, fibulin-4, and $\alpha$-actin, lead to perturbed mechanosensing and result in inadequate ECM remodeling and mechanical stress. This predisposes to aortic aneurysms [17, 60, 101, 144] (Fig. $3)$. In addition, these abnormalities in mechanosensing are paralleled by elevated local ACE expression and increased Ang II signaling [100]. This could be a consequence of the resulting mechanical stress, which has been demonstrated to upregulate local ACE expression [145] and to even directly stimulate the AT1R, in an Ang IIindependent manner [146, 147]. Therefore, it is most likely that elevated AT1R signaling in TAAs can best be prevented by ARBs and not by ACEi, as the latter can only prevent Ang II formation and not Ang IIindependent AT1R signaling.

Abnormalities in mechanosensing lead to increased expression of mechanosensing molecules, which could further contribute to elevated TGF- $\beta$ signaling, as observed in syndromic aortic aneurysms $[17,68,148-150]$. For instance, the mechanosensing molecule early growth response 1 (EGR1) has been shown to increase TGF- $\beta$ gene expression by binding to its promotor and activating its transcription. Also, EGR1 induces expression of thrombospondin (Thbs 1), another mechanosensing molecule that disturbs arterial wall integrity, activates ERK $1 / 2$ and latent TGF- $\beta$, and serves as an important mediator of Ang II-induced activation of TGF- $\beta$ in rat cardiac fibroblasts and mesangial cells [13, 17]. Notably, deletion of Thbs 1 in mice harboring a VSMCspecific knock-out of $F b \ln 4$ largely prevented TAA formation [17]. Thus, abnormal mechanosensing could contribute to aortic aneurysms by (1) hampering adequate ECM remodeling in response to hemodynamic loads, and (2) stimulation of local AT1R and TGF- $\beta$ signaling pathways, via mechanisms that involve mechanical stress and pathological upregulation of mechanosensing molecules (Fig. 3). Nonetheless, much of these mechanisms remain only partly understood and require further research. 


\section{ERK1/2 Signaling: Crosstalk Between RAS and TGF- $\beta$}

An important question that remains is how elevated Ang IIERK1/2 and TGF- $\beta$ signaling drive aneurysmal disease. The mitogen-activated protein kinase (MAPK) signaling pathway forms an important crosstalk between RAS and TGF- $\beta$ signaling: both Ang II and TGF- $\beta$, via non-canonical signaling, activate the 3 major MAP kinases: ERK1/2, JNK and p38 [36, 127]. Of these kinases, particularly ERK $1 / 2$ seems to be involved in aortic aneurysm formation, as the MAPK kinase (MEK) 1/2 inhibitor RDEA119 attenuated aortic root growth by selectively reducing ERK1/2 activation in $F b n 1^{C 1041 G+}$ mice, without affecting JNK and p38 activity [38]. In this study, ERK1/2-blockade was highly effective, as aortic root growth in this group was even indistinguishable from wildtype mice. Additionally, accumulation of phosphorylated ERK1/2 (pERK1/2), the active form of ERK1/2, was associated with aneurysm growth in $\mathrm{Fbnl} \mathrm{ClO4IG+}^{+}$mice, and both a TGF- $\beta$ neutralizing antibody and losartan were able to reduce pERK1/2 levels and to attenuate aneurysm expansion [37]. Notably, the MAPK pathway has also been shown to directly induce canonical TGF- $\beta$ signaling by phosphorylation and subsequent activation of R-SMAD proteins [36, 151], thereby forming a positive feedback loop (Fig. 3).

TGF- $\beta$ signaling induces expression of MMPs, such as $M M P 2$ and $M M P 9$, in aortic VSMC [127, 152-154], predominantly via non-canonical signaling pathways including ERK1/2 [155]. MMPs are involved in the degradation of ECM components and their activity is normally balanced by antagonizing tissue inhibitors of MMPs (TIMPs) to strictly control ECM turnover. Elevated TGF- $\beta$ - and ERK1/2induced MMP expression results in increased remodeling and incremental degradation of aortic connective tissue, which leads to weakness of the aortic wall. Consequently, the aortic capacity to endure biomechanical forces is reduced, which predisposes to aneurysm development $[57,153]$. Indeed, a signature of elevated MMP expression is found in tissue samples from TAA patients $[153,156]$. MMP inhibition could therefore have therapeutic potential, as evidenced by the observation that the MMP inhibitor doxycycline was more potent in preventing TAA and to preserve elastic fiber integrity than the $\beta$-blocker atenolol in $F b n 1^{C 1041 G+}$ mice [157]. The beneficial effects of doxycycline on thoracic aortic pathology were also observed in other MFS mouse models $\left(F b n 1^{C 1041 G /+}\right.$ and Fbn $\left.1^{m g R / m g R}\right)[158,159]$. However, MMPs do not seem to contribute to TAAs under all circumstances, as another preclinical study demonstrated that MMP2-deficiency actually accelerated dilatation of the thoracic aorta during Ang II infusion. Although this model may not fully mimic syndromic TAA patients, it demonstrates that a balance between Ang II and MMPs is essential to maintain ECM homeostasis. Another mechanism by which MMPs could contribute to aneurysm formation is by further increasing TGF- $\beta$ signaling [30]. This is evidenced by the observation that activation of TGF- $\beta$ and subsequent activation of the pSMAD2/3 pathway was hampered in MMP2-deficient mice [160]. Besides, TGF- $\beta$ is normally sequestered in the ECM and increased ECM degradation mediated by MMPs could result in a greater TGF- $\beta$ bioavailability [62]. Next to increased MMP expression, both AT1R signaling and TGF- $\beta$ increase genetic expression of several profibrotic factors, such as connective tissue growth factor and plasminogen activator inhibitor-1 [161]. These factors may further impair aortic wall homeostasis by increasing aortic wall stiffness [161], which is an independent predictor of progressive aortic dilatation in MFS patients [162].

As stated, blockade of TGF- $\beta$ signaling too early exacerbates aortic pathology [114]. Therefore, a better approach might be to specifically inhibit Ang II-AT1R-driven TGF- $\beta$ overactivation, rather than TGF- $\beta$ signaling in general. ARBs antagonize TGF- $\beta$ overexpression in mice with chronic renal insufficiency and cardiomyopathy [163, 164]. Additionally, mechanical stress from disruptions in mechanosensing could theoretically be reduced by drugs that decrease hemodynamic load, such as $\beta$-blockers or alternative antihypertensive drugs.

\section{Clinical Trials in Syndromic TAA Patients}

Over the past 2 decades, multiple randomized controlled trials have been performed to investigate the potency of ARBs and $\beta$-blockers to limit aortic aneurysm growth in the clinical situation (Table 3). Of note, all studies were performed in MFS patients and most trials used aortic (root) growth as a surrogate outcome for aneurysm rupture or dissection.

Brooke et al. [165] were the first to examine the clinical benefits of ARBs on TAA pathology. In a retrospective study, they demonstrated that ARB usage was associated with reduced aortic root growth in severely affected pediatric MFS patients. Multiple randomized controlled trials followed [129, 130, 166-171] (Table 3). In 2013, the randomized open-label controlled COMPARE trial was published, which investigated the potential benefit of adding losartan to standard care, including a $\beta$-blocker in $>70 \%$ of the patients [129]. After 3 years of follow-up, aortic root aneurysm growth was significantly lower in the losartan group vs. the standard care group, confirming the previous retrospective results [165]. Although mean arterial blood pressure was slightly lower in the losartan group, no correlation between blood pressure levels and aortic root dimensions was found. This suggests that the beneficial effects of losartan are, at least partially, independent of its effects on blood pressure. This might be attributed to its inhibitory effects on TGF- $\beta$ and ERK1/2-signaling, but clinical measurements to validate this hypothesis are lacking. 


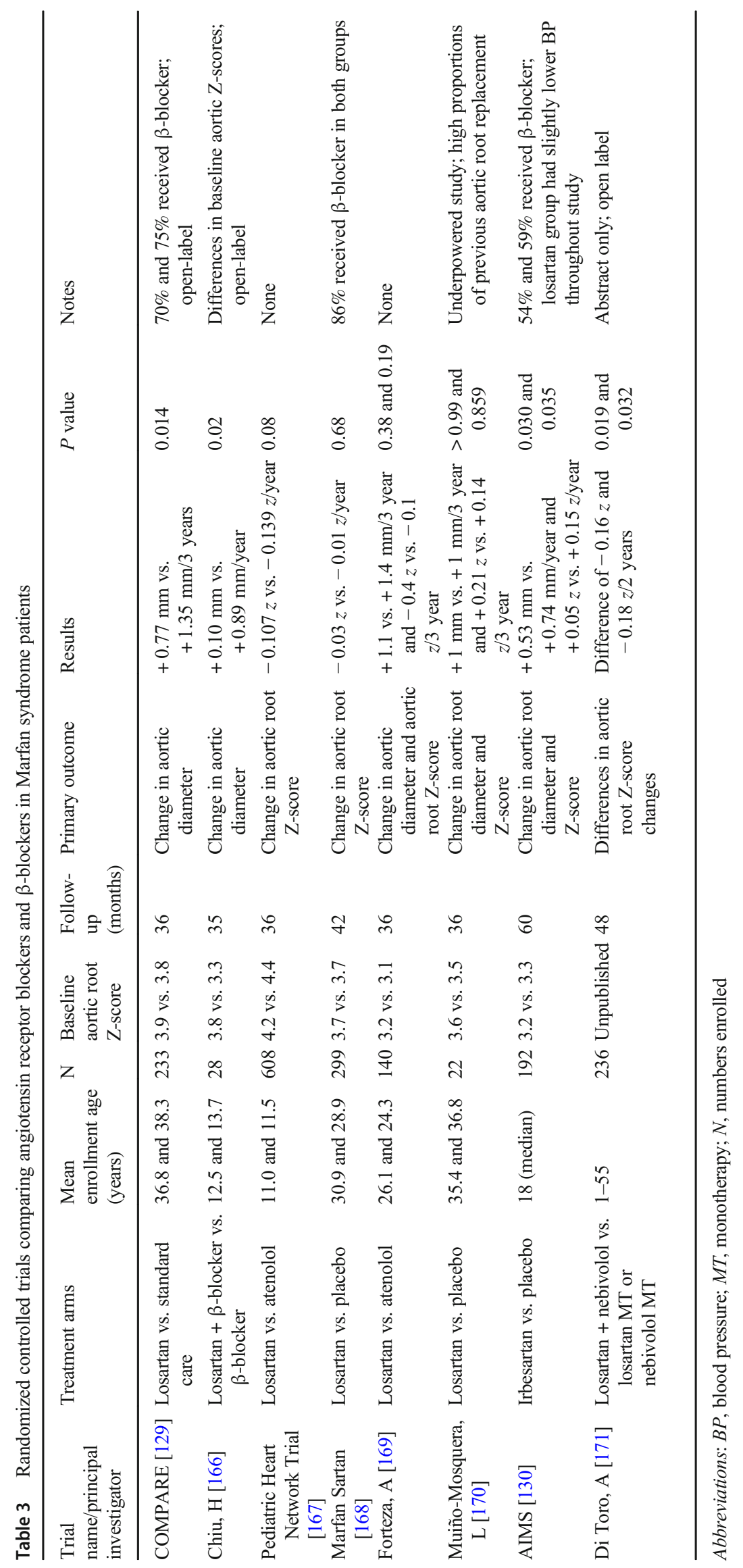




\section{ARBs vs. $\beta$-Blockers}

Several trials compared the efficacy of ARB monotherapy with $\beta$-blocker monotherapy to prevent aortic root expansion in MFS patients $[167,169,172]$. This is particularly interesting as the usage of $\beta$-blockers, the current mainstay of treatment, is predominantly based on the results of a single clinical trial, published in 1994 [173]. This trial had many limitations, such as a very limited sample size, unblinded treatment allocation, a lack of control on drug compliance and inclusion of deaths in the analyses that were unrelated to aortic pathology [174]. Also, a recent Cochrane review stated that no clear treatment recommendation regarding the use of $\beta$-blockers in MFS could be made [175]. Therefore, solid evidence of the beneficial effects of $\beta$-blockers in MFS patients is lacking [176]. Notably, none of the performed trials reported superiority of $\beta$-blockers over ARBs. The largest among them, the Pediatric Heart Network Trial [167], compared losartan with the $\beta$-blocker atenolol in 608 young MFS patients. After 3 years of followup, both drugs were equally effective in attenuating aortic root dilatation. These results were verified by a Spanish randomized controlled trial with a similar design [169]. Nonetheless, a recent review [177] suggests that caution concerning ARBs as first-line monotherapy is warranted, as adverse events were almost twice as common in the losartan group compared to the atenolol group in the Pediatric Heart Network Trial. However, in the Spanish randomized controlled trial, only 1 serious adverse event occurred in the losartan group, compared with 4 in the atenolol group [169]. Importantly, neither trials reached statistical significance regarding these adverse endpoints $[167,169]$. In addition, an extension study of the Spanish trial by Forteza et al. found no differences in adverse outcomes in the losartan vs. the atenolol group after a median follow-up period of 6.7 years [178]. Thus, ARBs do not seem to be inferior to $\beta$-blockers in attenuating aortic root growth in MFS patients and display a similar long-term safety profile.

\section{ARBs and $\beta$-Blockers: Synergy?}

Interestingly, other studies examined potential synergistic effects of combining a $\beta$-blocker with an ARB in syndromic TAAs. Although a synergy between $\beta$-blockers and ARBs was observed in a small, open-label randomized controlled trial [166], the beneficial effects of add-on losartan therapy were not confirmed by the Ghent Marfan Trial [170]. Perhaps this study was underpowered, but the much larger French Marfan Sartan trial also failed to confirm this synergy [168]. In this latter study, $86 \%$ of the 303 included MFS patients used $\beta$-blocker therapy at baseline. After a median follow-up of 3.5 years, the addition of 50-100 mg losartan did not result in a slower dilatation of the aortic root compared with placebo. Notably, this lack of synergy between ARBs and $\beta$-blockers was challenged by the COMPARE trial
[129] and, more recently, by the multicenter randomized controlled AIMS trial [130]. The AIMS trial demonstrated that addition of the ARB irbesartan to usual care significantly decreased aortic root growth compared to placebo. In this add-on irbesartan group, 54\% used concomitant $\beta$-blocker therapy and mean blood pressure levels were slightly lower, which could contribute to the observed differences.

Notably, all randomized clinical trials examined aortic dilatation, but none had sufficient statistical power to detect any differences in the clinically most relevant outcomes, such as aortic dissection, aortic rupture and mortality. Therefore, the results from the recently published long-term follow-up study of the COMPARE trial are highly relevant [179]. After a median follow-up period of 8 years, a clear reduction in several adverse clinical endpoints, such as all-cause mortality and aortic dissection, was observed in the patient group that used losartan during the entire follow-up period. Interestingly, $81 \%$ of these patients used concomitant $\beta$-blockade therapy. In addition, a recent meta-analysis demonstrated that the addition of an ARB to $\beta$-blocker therapy reduced the rate of aortic root dilatation, but did not significantly reduce the number of aortic complications [180]. This latter result could be a consequence of low statistical power to demonstrate differences in these complications due to low event rates. Also, this metaanalysis did not include the long-term follow-up study from the COMPARE trial [179]. Thus, when taking the results from the COMPARE, AIMS, and the long-term follow-up study of the COMPARE trial together, it seems that combining ARBs and $\beta$-blockers in MFS patients is not only preferential to prevent aneurysm growth but also to prevent long-term adverse outcomes [129, 130, 179].

\section{Differences Between Preclinical and Clinical Studies}

Unfortunately, the promising preclinical results of ARBs to attenuate TAA expansion $[37,106]$ were not unequivocally reproduced in the clinical setting and the observed discrepancy was remarkable. Several reasons could underlie the seemingly lack of consistent results in the human situation. Firstly, the efficacy of ARB treatment might be determined by the type and dosage of ARB used. The AIMS trial demonstrated that addition of irbesartan to usual care was beneficial, whereas losartan did not lead to superior treatment outcomes in the Marfan Sartan Trial. As irbesartan has a much longer half-life and a greater bioavailability than losartan [181], this could indicate that losartan dosages in previous studies were insufficient to fully benefit from its protective effects. Indeed, atenolol was administered in much higher dosages than losartan in the Pediatric Heart Network Trial which led the authors to conclude that a higher dose of losartan or a different ARB might yield superior results [167]. Previously, it has been suggested that administered dosages of RAS inhibitors, including $\mathrm{ARBs}$, in the range to reduce blood pressure are insufficient to 
effectively normalize TGF- $\beta$ overexpression [182]. Provided that these higher ARB dosages are well-tolerated by the included patients, it would be interesting to study if these higher dosages can attenuate aortic dilatation more effectively.

Secondly, it could be essential to start ARB treatment early in aneurysm development. We hypothesize that elevated aortic Ang II-AT1R signaling is an important driver for excessive TGF- $\beta$ signaling in the context of syndromic TAAs. Consequently, early specific inhibition of Ang II-AT1R signaling is necessary to prevent this detrimental TGF- $\beta$ upregulation, but still allowing for RAS-independent basal TGF- $\beta$ signaling to occur. Indeed, a preclinical study demonstrated that losartan prevented aneurysm formation in a VSMC-specific Fbln 4 knock-out mouse model when initiated from postnatal day 7 , whereas this treatment lost its efficacy when initiated at a later time point [100]. Also, in the hallmark trial showing the beneficial effect of losartan in $\mathrm{Fbnl}^{\mathrm{ClO} 104 \mathrm{G} / \mathrm{+}}$ mice, this treatment was started prenatally [106]. How this critical treatment time window can be translated to the human situation needs further investigation. Also, determinants other than age, such as aortic root Zscores, may be better indicators when to initiate medical treatment, as they better reflect aortic disease stage. In addition, higher circulating TGF- $\beta$ levels are associated with more advanced stages and higher rates of aortic dilatation in TAA patients [149]. In this regard, it would be interesting to investigate if circulating TGF- $\beta$ levels could be used as a biomarker for the severity of aortic pathology, in concordance with other possible biomarkers [183]. Of note, factors other than Ang II can also directly stimulate the AT1R in syndromic TAAs, such as mechanical stress due to disturbed mechanosensing. Therefore, specific direct inhibition of AT1R signaling via ARBs, rather than inhibition of Ang II via ACEi, is supposed to yield the most optimal treatment outcomes, although a direct comparison has not been made in syndromic TAA patients.

Thirdly, results from preclinical studies are based on a limited number of mouse models, harboring identical mutations in the Fbn1 gene (Table 1) [14]. In contrast, more than 1000 mutations in FBN1 have been identified in human MFS patients $[184,185]$. Therefore, these preclinical studies do not adequately represent the genetic heterogeneity found in MFS patients and this could hamper the translation of promising preclinical results into the clinical situation.

Fourthly, this genetic heterogeneity in MFS patients can also be an underlying cause for the differences in treatment outcomes observed between clinical trials. Most clinical studies did not assess nor stratify for the underlying FBN1 mutation. As a consequence, these mutations might not be equally distributed among treatment groups and between different studies. Of note, characterizing the underlying $F B N 1$ mutation is extremely relevant, as the type of mutation determines the clinical course and severity of aortic pathology in MFS patients [186, 187]. Also, it predicts the efficacy of losartan therapy: in a substudy of the COMPARE trial, MFS patients carrying a haploinsufficient $F B N 1$ mutation responded better to losartan therapy than those harboring a dominant-negative mutation [188]. Therefore, differences in underlying FBN1 mutations could be another reason for the observed variability of treatment effects in clinical trials.

To summarize, multiple factors seem to underlie the observed differences between the preclinical and clinical situation. Therefore, the results from the announced prospective meta-analysis, combining all previous randomized controlled trials on ARB and $\beta$-blocker treatment in MFS, are eagerly awaited [189]. Hopefully, this meta-analysis will clarify the therapeutic potential of these compounds in different MFS subgroups, such as clustered by age, aortic Z-score, or type of FBN1-mutation, on the most relevant clinical outcomes.

\section{Conclusions and Future Directions}

Over the past decades, a better understanding of the molecular mechanisms leading to the formation of syndromic TAAs has been obtained. Elevated signaling of the TGF- $\beta$ pathway is observed in syndromic TAA patients, which could be due to increased local RAS signaling. These pathways are likely to act in concert to induce aortic pathology by mechanisms that remain subject of investigation, but at least include stimulation of aortic ECM degradation and aortic fibrosis. However, how elevated RAS signaling occurs in the context of TAAs is yet to be fully elucidated. Mechanical stress resulting from disruption in mechanosensing abilities of aortic VSMCs might be one of the contributors. Importantly, preclinical evidence suggests that targeting the TGF- $\beta$ pathway too early in aortic aneurysm formation leads to worsening of aortic pathology. Thus, clinical treatment in affected TAA patients should ideally be directed at both RAS and TGF- $\beta$ signaling, although sparing the early protective role of the latter. In this regard, biomarkers indicating the stage of aortic disease could be of additional value. Also, higher ARB dosages combined with therapeutic modalities that reduce mechanical stress, such as $\beta$-blockers, might be preferential. As ERK1/2 also seems to play a crucial role, an alternative treatment strategy might be to specifically inhibit ERK1/2-signaling in syndromic TAAs patients. Such drugs are currently being investigated in the field of oncology [190].

Importantly, to the best of our knowledge, all clinical trials investigating the efficacy of ARBs and $\beta$-blockers on aortic pathology were performed in MFS individuals. Unfortunately, these clinical trials did not confirm the promising results from preclinical studies. Several reasons could underlie these differences, including wide genetic heterogeneity among the MFS population, which affects disease severity and treatment efficacy. Hopefully, future research will take these genetic aspects into account. A difficulty to overcome is the fact that only a limited number of patients for each specific mutation 
are available. Also in this light, caution is warranted regarding the extrapolation of results from the MFS study population to patients with other TAA syndromes, such as LDS, and more research is needed in these individual patients and patient populations. In this regard, bioinformatic predictions on the consequences of different mutations might be useful to form more specific, but large enough study groups and investigate treatment outcomes in these subgroups. This knowledge can be combined with new developments in induced pluripotent stem cells technology, for which patient material can be used to improve and accelerate the translation of preclinical findings into the clinical situation [191]. Combining these techniques with new integrative approaches coupling genomics, transcriptomics, proteomics, and functional experiments [62, 192] could pave the way for novel targeted and more individualized treatment regimens for syndromic TAA patients.

Authors' Contribution Daan C.H. van Dorst, Jeroen Essers, and A.H. Jan Danser generated the concept for this review, Daan C.H. van Dorst and Nathalie P. de Wagenaar performed the literature search, and Daan C.H. van Dorst, Nathalie P. de Wagenaar, Ingrid van der Pluijm, Jolien W. Roos-Hesselink, Jeroen Essers, and A.H. Jan Danser drafted and/or critically revised the work.

Funding Nathalie P. De Wagenaar is funded by Erasmus MC Mrace grant and Jolien W. Roos-Hesselink is funded by the Erasmus MC Thorax Foundation.

Data Availability PubMed, Embase, Web of Science, and Cochrane Library search.

\section{Compliance with Ethical Standards}

Conflict of Interest The authors declare that they have no conflict of interest.

\section{Ethics Approval Not applicable}

Open Access This article is licensed under a Creative Commons Attribution 4.0 International License, which permits use, sharing, adaptation, distribution and reproduction in any medium or format, as long as you give appropriate credit to the original author(s) and the source, provide a link to the Creative Commons licence, and indicate if changes were made. The images or other third party material in this article are included in the article's Creative Commons licence, unless indicated otherwise in a credit line to the material. If material is not included in the article's Creative Commons licence and your intended use is not permitted by statutory regulation or exceeds the permitted use, you will need to obtain permission directly from the copyright holder. To view a copy of this licence, visit http://creativecommons.org/licenses/by/4.0/.

\section{References}

1. Hiratzka LF, Bakris GL, Beckman JA, Bersin RM, Carr VF, Casey DE, Jr. et al. 2010 ACCF/AHA/AATS/ACR/ASA/SCA/ SCAI/SIR/STS/SVM guidelines for the diagnosis and management of patients with Thoracic Aortic Disease: a report of the
American College of Cardiology Foundation/American Heart Association Task Force on Practice Guidelines, American Association for Thoracic Surgery, American College of Radiology, American Stroke Association, Society of Cardiovascular Anesthesiologists, Society for Cardiovascular Angiography and Interventions, Society of Interventional Radiology, Society of Thoracic Surgeons, and Society for Vascular Medicine. Circulation. 2010;121:e266-e369.

2. Melvinsdottir IH, Lund SH, Agnarsson BA, Sigvaldason K, Gudbjartsson T, Geirsson A. The incidence and mortality of acute thoracic aortic dissection: results from a whole nation study. Eur J Cardiothorac Surg. 2016;50:1111-7.

3. Davies RR, Goldstein LJ, Coady MA, Tittle SL, Rizzo JA, Kopf GS, et al. Yearly rupture or dissection rates for thoracic aortic aneurysms: simple prediction based on size. Ann Thorac Surg. 2002;73:17-27 discussion -8 .

4. Elefteriades JA. Natural history of thoracic aortic aneurysms: indications for surgery, and surgical versus nonsurgical risks. Ann Thorac Surg. 2002;74:S1877-80 discussion S92-8.

5. Erbel R, Aboyans V, Boileau C, Bossone E, Bartolomeo RD, Eggebrecht H, et al. 2014 ESC Guidelines on the diagnosis and treatment of aortic diseases: document covering acute and chronic aortic diseases of the thoracic and abdominal aorta of the adult. The Task Force for the Diagnosis and Treatment of Aortic Diseases of the European Society of Cardiology (ESC). Eur Heart J. 2014;35:2873-926.

6. Isselbacher EM, Lino Cardenas CL, Lindsay ME. Hereditary influence in thoracic aortic aneurysm and dissection. Circulation. 2016;133:2516-28.

7. Albornoz G, Coady MA, Roberts M, Davies RR, Tranquilli M, Rizzo JA, et al. Familial thoracic aortic aneurysms and dissections-incidence, modes of inheritance, and phenotypic patterns. Ann Thorac Surg. 2006;82:1400-5.

8. Judge DP, Dietz HC. Marfan's syndrome. Lancet. 2005;366: 1965-76.

9. MacCarrick G, Black JH 3rd, Bowdin S, El-Hamamsy I, Frischmeyer-Guerrerio PA, Guerrerio AL, et al. Loeys-Dietz syndrome: a primer for diagnosis and management. Genet Med. 2014;16:576-87.

10. Lindsay ME, Dietz HC. Lessons on the pathogenesis of aneurysm from heritable conditions. Nature. 2011;473:308-16.

11. Andelfinger G, Loeys B, Dietz H. A decade of discovery in the genetic understanding of thoracic aortic disease. Can J Cardiol. 2016;32:13-25.

12. Mallat $\mathrm{Z}$, Ait-Oufella H, Tedgui A. The pathogenic transforming growth factor- $\beta$ overdrive hypothesis in aortic aneurysms and dissections: a mirage? Circ Res. 2017;120:1718-20.

13. Zhou Y, Poczatek MH, Berecek KH, Murphy-Ullrich JE. Thrombospondin 1 mediates angiotensin II induction of TGFbeta activation by cardiac and renal cells under both high and low glucose conditions. Biochem Biophys Res Commun. 2006;339:633-41.

14. Moltzer E, Essers J, van Esch JH, Roos-Hesselink JW, Danser $\mathrm{AH}$. The role of the renin-angiotensin system in thoracic aortic aneurysms: clinical implications. Pharmacol Ther. 2011;131:50 60.

15. Forrester SJ, Booz GW, Sigmund CD, Coffman TM, Kawai T, Rizzo V, et al. Angiotensin II signal transduction: an update on mechanisms of physiology and pathophysiology. Physiol Rev. 2018;98:1627-738.

16. Milewicz DM, Prakash SK, Ramirez F. Therapeutics targeting drivers of thoracic aortic aneurysms and acute aortic dissections: insights from predisposing genes and mouse models. Annu Rev Med. 2017;68:51-67.

17. Yamashiro Y, Thang BQ, Shin SJ, Lino CA, Nakamura T, Kim J, et al. Role of thrombospondin- 1 in mechanotransduction and 
development of thoracic aortic aneurysm in mouse and humans. Circ Res. 2018;123:660-72.

18. Rahimi RA, Leof EB. TGF-beta signaling: a tale of two responses. J Cell Biochem. 2007;102:593-608.

19. Lawrence DA. Transforming growth factor-beta: a general review. Eur Cytokine Netw. 1996;7:363-74.

20. Laverty HG, Wakefield LM, Occleston NL, O'Kane S, Ferguson MW. TGF-beta3 and cancer: a review. Cytokine Growth Factor Rev. 2009;20:305-17.

21. Boileau C, Guo DC, Hanna N, Regalado ES, Detaint D, Gong L, et al. TGFB2 mutations cause familial thoracic aortic aneurysms and dissections associated with mild systemic features of Marfan syndrome. Nat Genet. 2012;44:916-21.

22. Bertoli-Avella AM, Gillis E, Morisaki H, Verhagen JMA, de Graaf BM, van de Beek G, et al. Mutations in a TGF- $\beta$ ligand, TGFB3, cause syndromic aortic aneurysms and dissections. J Am Coll Cardiol. 2015;65:1324-36.

23. Daugherty A, Chen Z, Sawada H, Rateri DL, Sheppard MB. Transforming growth factor- $\beta$ in thoracic aortic aneurysms: good, bad, or irrelevant? J Am Heart Assoc. 2017;6.

24. Robertson IB, Horiguchi M, Zilberberg L, Dabovic B, Hadjiolova $\mathrm{K}$, Rifkin DB. Latent TGF- $\beta$-binding proteins. Matrix Biol. 2015;47:44-53.

25. Ramirez F, Rifkin DB. Extracellular microfibrils: contextual platforms for TGFbeta and BMP signaling. Curr Opin Cell Biol. 2009;21:616-22.

26. Isogai Z, Ono RN, Ushiro S, Keene DR, Chen Y, Mazzieri R, et al. Latent transforming growth factor beta-binding protein 1 interacts with fibrillin and is a microfibril-associated protein. J Biol Chem. 2003;278:2750-7.

27. Neptune ER, Frischmeyer PA, Arking DE, Myers L, Bunton TE, Gayraud B, et al. Dysregulation of TGF-beta activation contributes to pathogenesis in Marfan syndrome. Nat Genet. 2003;33: $407-11$

28. Annes JP, Munger JS, Rifkin DB. Making sense of latent TGFbeta activation. J Cell Sci. 2003;116:217-24.

29. Sato Y, Rifkin DB. Inhibition of endothelial cell movement by pericytes and smooth muscle cells: activation of a latent transforming growth factor-beta 1-like molecule by plasmin during co-culture. J Cell Biol. 1989;109:309-15.

30. Yu Q, Stamenkovic I. Cell surface-localized matrix metalloproteinase-9 proteolytically activates TGF-beta and promotes tumor invasion and angiogenesis. Genes Dev. 2000;14: 163-76.

31. Schultz-Cherry S, Murphy-Ullrich JE. Thrombospondin causes activation of latent transforming growth factor-beta secreted by endothelial cells by a novel mechanism. J Cell Biol. 1993;122: 923-32.

32. Munger JS, Huang X, Kawakatsu H, Griffiths MJ, Dalton SL, Wu $\mathrm{J}$, et al. The integrin alpha $\mathrm{v}$ beta 6 binds and activates latent TGF beta 1: a mechanism for regulating pulmonary inflammation and fibrosis. Cell. 1999;96:319-28.

33. Chaudhry SS, Cain SA, Morgan A, Dallas SL, Shuttleworth CA, Kielty CM. Fibrillin-1 regulates the bioavailability of TGFbeta1. J Cell Biol. 2007;176:355-67.

34. Wrana JL, Attisano L, Wieser R, Ventura F, Massagué J. Mechanism of activation of the TGF-beta receptor. Nature. 1994;370:341-7.

35. Heldin $\mathrm{CH}$, Miyazono $\mathrm{K}$, ten Dijke P. TGF-beta signalling from cell membrane to nucleus through SMAD proteins. Nature. 1997;390:465-71.

36. Zhang YE. Non-Smad pathways in TGF-beta signaling. Cell Res. 2009;19:128-39.

37. Habashi JP, Doyle JJ, Holm TM, Aziz H, Schoenhoff F, Bedja D, et al. Angiotensin II type 2 receptor signaling attenuates aortic aneurysm in mice through ERK antagonism. Science. 2011;332: 361-5.

38. Holm TM, Habashi JP, Doyle JJ, Bedja D, Chen Y, van Erp C, et al. Noncanonical TGF $\beta$ signaling contributes to aortic aneurysm progression in Marfan syndrome mice. Science. 2011;332: 358-61.

39. van der Pluijm I, van Vliet N, von der Thusen JH, Robertus JL, Ridwan Y, van Heijningen PM, et al. Defective connective tissue remodeling in Smad3 mice leads to accelerated aneurysmal growth through disturbed downstream TGF- $\beta$ signaling. EBioMedicine. 2016;12:280-94.

40. Tingting T, Wenjing F, Qian Z, Hengquan W, Simin Z, Zhisheng $\mathrm{J}$, et al. The TGF- $\beta$ pathway plays a key role in aortic aneurysms. Clin Chim Acta. 2020;501:222-8.

41. Vander Ark A, Cao J, Li X. TGF- $\beta$ receptors: in and beyond TGF$\beta$ signaling. Cell Signal. 2018;52:112-20.

42. Hata A, Chen YG. TGF- $\beta$ signaling from receptors to Smads. Cold Spring Harb Perspect Biol. 2016;8.

43. Miyazono K, ten Dijke P, Heldin CH. TGF-beta signaling by Smad proteins. Adv Immunol. 2000;75:115-57.

44. Miyazono K. TGF-beta signaling by Smad proteins. Cytokine Growth Factor Rev. 2000;11:15-22.

45. Heldin $\mathrm{CH}$, Moustakas A. Role of Smads in TGF $\beta$ signaling. Cell Tissue Res. 2012;347:21-36.

46. Massagué J. TGF $\beta$ signalling in context. Nat Rev Mol Cell Biol. 2012;13:616-30.

47. Massagué J. TGF-beta signal transduction. Annu Rev Biochem. 1998;67:753-91

48. Hanyu A, Ishidou $Y$, Ebisawa $T$, Shimanuki T, Imamura T, Miyazono K. The N domain of Smad7 is essential for specific inhibition of transforming growth factor-beta signaling. J Cell Biol. 2001;155:1017-27.

49. Goto K, Kamiya Y, Imamura T, Miyazono K, Miyazawa K. Selective inhibitory effects of Smad6 on bone morphogenetic protein type I receptors. J Biol Chem. 2007;282:20603-11.

50. Hayashi H, Abdollah S, Qiu Y, Cai J, Xu YY, Grinnell BW, et al. The MAD-related protein Smad7 associates with the TGFbeta receptor and functions as an antagonist of TGFbeta signaling. Cell. 1997;89:1165-73.

51. Nakao A, Afrakhte M, Morén A, Nakayama T, Christian JL, Heuchel R, et al. Identification of Smad7, a TGFbeta-inducible antagonist of TGF-beta signalling. Nature. 1997;389:631-5.

52. Imamura T, Takase M, Nishihara A, Oeda E, Hanai J, Kawabata M, et al. Smad6 inhibits signalling by the TGF-beta superfamily. Nature. 1997;389:622-6.

53. Suzuki H, Yagi K, Kondo M, Kato M, Miyazono K, Miyazawa K. c-Ski inhibits the TGF-beta signaling pathway through stabilization of inactive Smad complexes on Smad-binding elements. Oncogene. 2004;23:5068-76.

54. Zhang YE. Non-Smad signaling pathways of the TGF- $\beta$ family. Cold Spring Harb Perspect Biol. 2017;9.

55. Kalluri R, Weinberg RA. The basics of epithelial-mesenchymal transition. J Clin Invest. 2009;119:1420-8.

56. Luo K. Signaling cross talk between TGF- $\beta /$ Smad and other signaling pathways. Cold Spring Harb Perspect Biol. 2017;9.

57. Verstraeten A, Luyckx I, Loeys B. Aetiology and management of hereditary aortopathy. Nat Rev Cardiol. 2017;14:197-208.

58. Regalado ES, Guo DC, Santos-Cortez RL, Hostetler E, Bensend TA, Pannu H, et al. Pathogenic FBN1 variants in familial thoracic aortic aneurysms and dissections. Clin Genet. 2016;89:719-23.

59. Weerakkody R, Ross D, Parry DA, Ziganshin B, Vandrovcova J, Gampawar P, et al. Targeted genetic analysis in a large cohort of familial and sporadic cases of aneurysm or dissection of the thoracic aorta. Genet Med. 2018;20:1414-22. 
60. Dietz HC, Cutting GR, Pyeritz RE, Maslen CL, Sakai LY, Corson GM, et al. Marfan syndrome caused by a recurrent de novo missense mutation in the fibrillin gene. Nature. 1991;352:337-9.

61. Davis MR, Summers KM. Structure and function of the mammalian fibrillin gene family: implications for human connective tissue diseases. Mol Genet Metab. 2012;107:635-47.

62. Barallobre-Barreiro J, Loeys B, Mayr M, Rienks M, Verstraeten A, Kovacic JC. Extracellular matrix in vascular disease, part 2/4: JACC Focus Seminar. J Am Coll Cardiol. 2020;75:2189-203.

63. LeMaire SA, Russell L. Epidemiology of thoracic aortic dissection. Nat Rev Cardiol. 2011;8:103-13.

64. Meester JA, Vandeweyer G, Pintelon I, Lammens M, Van Hoorick L, De Belder S, et al. Loss-of-function mutations in the $\mathrm{X}$-linked biglycan gene cause a severe syndromic form of thoracic aortic aneurysms and dissections. Genet Med. 2017;19:386-95.

65. Heegaard AM, Corsi A, Danielsen CC, Nielsen KL, Jorgensen HL, Riminucci M, et al. Biglycan deficiency causes spontaneous aortic dissection and rupture in mice. Circulation. 2007;115:27318.

66. Hucthagowder V, Sausgruber N, Kim KH, Angle B, Marmorstein LY, Urban Z. Fibulin-4: a novel gene for an autosomal recessive cutis laxa syndrome. Am J Hum Genet. 2006;78:1075-80.

67. Sasaki T, Hanisch FG, Deutzmann R, Sakai LY, Sakuma T, Miyamoto T, et al. Functional consequence of fibulin-4 missense mutations associated with vascular and skeletal abnormalities and cutis laxa. Matrix Biol. 2016;56:132-49.

68. Loeys BL, Chen J, Neptune ER, Judge DP, Podowski M, Holm T, et al. A syndrome of altered cardiovascular, craniofacial, neurocognitive and skeletal development caused by mutations in TGFBR1 or TGFBR2. Nat Genet. 2005;37:275-81.

69. van de Laar IM, van der Linde D, Oei EH, Bos PK, Bessems JH, Bierma-Zeinstra SM, et al. Phenotypic spectrum of the SMAD3related aneurysms-osteoarthritis syndrome. J Med Genet. 2012;49:47-57.

70. van de Laar IM, Oldenburg RA, Pals G, Roos-Hesselink JW, de Graaf BM, Verhagen JM, et al. Mutations in SMAD3 cause a syndromic form of aortic aneurysms and dissections with earlyonset osteoarthritis. Nat Genet. 2011;43:121-6.

71. Micha D, Guo DC, Hilhorst-Hofstee Y, van Kooten F, Atmaja D, Overwater E, et al. SMAD2 mutations are associated with arterial aneurysms and dissections. Hum Mutat. 2015;36:1145-9.

72. Cannaerts E, Kempers M, Maugeri A, Marcelis C, Gardeitchik T, Richer J, et al. Novel pathogenic SMAD2 variants in five families with arterial aneurysm and dissection: further delineation of the phenotype. J Med Genet. 2019;56:220-7.

73. Meester JAN, Verstraeten A, Schepers D, Alaerts M, Van Laer L, Loeys BL. Differences in manifestations of Marfan syndrome, Ehlers-Danlos syndrome, and Loeys-Dietz syndrome. Ann Cardiothorac Surg. 2017;6:582-94.

74. Loeys BL DHL-DSFUMIAM, Ardinger HH, Pagon RA, et al., editors. GeneReviews ${ }^{\circledR}$ [Internet]. Seattle (WA): University of Washington, Seattle; 1993-2020. Available from: https://www. ncbi.nlm.nih.gov/books/NBK1133/.

75. Aalberts JJ, van den Berg MP, Bergman JE, du Marchie Sarvaas GJ, Post JG, van Unen H, et al. The many faces of aggressive aortic pathology: Loeys-Dietz syndrome. Neth Heart J. 2008;16: 299-304.

76. van den Hoven AT, Bons LR, Baart SJ, Moelker A, van de Laar I, van den Bosch AE, et al. Aortic dimensions and clinical outcome in patients with SMAD3 mutations. Circ Genom Precis Med. 2018;11:e002329.

77. Vorselaars VMM, Diederik A, Prabhudesai V, Velthuis S, Vos JA, Snijder RJ, et al. SMAD4 gene mutation increases the risk of aortic dilation in patients with hereditary haemorrhagic telangiectasia. Int J Cardiol. 2017;245:114-8.
78. Doyle AJ, Doyle JJ, Bessling SL, Maragh S, Lindsay ME, Schepers D, et al. Mutations in the TGF- $\beta$ repressor SKI cause Shprintzen-Goldberg syndrome with aortic aneurysm. Nat Genet. 2012;44:1249-54.

79. Schepers D, Doyle AJ, Oswald G, Sparks E, Myers L, Willems PJ, et al. The SMAD-binding domain of SKI: a hotspot for de novo mutations causing Shprintzen-Goldberg syndrome. Eur J Hum Genet. 2015;23:224-8.

80. Gillis E, Kumar AA, Luyckx I, Preuss C, Cannaerts E, van de Beek G, et al. Candidate gene resequencing in a large bicuspid aortic valve-associated thoracic aortic aneurysm cohort: SMAD6 as an important contributor. Front Physiol. 2017;8:400.

81. Carta L, Pereira L, Arteaga-Solis E, Lee-Arteaga SY, Lenart B, Starcher B, et al. Fibrillins 1 and 2 perform partially overlapping functions during aortic development. J Biol Chem. 2006;281: 8016-23.

82. Pereira L, Andrikopoulos K, Tian J, Lee SY, Keene DR, Ono R, et al. Targetting of the gene encoding fibrillin-1 recapitulates the vascular aspect of Marfan syndrome. Nat Genet. 1997;17:218-22.

83. Charbonneau NL, Carlson EJ, Tufa S, Sengle G, Manalo EC, Carlberg VM, et al. In vivo studies of mutant fibrillin-1 microfibrils. J Biol Chem. 2010;285:24943-55.

84. Pereira L, Lee SY, Gayraud B, Andrikopoulos K, Shapiro SD, Bunton T, et al. Pathogenetic sequence for aneurysm revealed in mice underexpressing fibrillin-1. Proc Natl Acad Sci U S A. 1999;96:3819-23.

85. Judge DP, Biery NJ, Keene DR, Geubtner J, Myers L, Huso DL, et al. Evidence for a critical contribution of haploinsufficiency in the complex pathogenesis of Marfan syndrome. J Clin Invest. 2004; 114:172-81.

86. Groth KA, Stochholm K, Hove H, Andersen NH, Gravholt CH. Causes of mortality in the Marfan syndrome (from a Nationwide register study). Am J Cardiol. 2018;122:1231-5.

87. von Kodolitsch Y, Robinson PN. Marfan syndrome: an update of genetics, medical and surgical management. Heart. 2007;93:755-60.

88. Murdoch JL, Walker BA, Halpern BL, Kuzma JW, McKusick VA. Life expectancy and causes of death in the Marfan syndrome. N Engl J Med. 1972;286:804-8.

89. Ye P, Chen W, Wu J, Huang X, Li J, Wang S, et al. GM-CSF contributes to aortic aneurysms resulting from SMAD3 deficiency. J Clin Invest. 2013;123:2317-31.

90. Carvalho RL, Itoh F, Goumans MJ, Lebrin F, Kato M, Takahashi $\mathrm{S}$, et al. Compensatory signalling induced in the yolk sac vasculature by deletion of TGFbeta receptors in mice. J Cell Sci. 2007;120:4269-77.

91. Oshima M, Oshima H, Taketo MM. TGF-beta receptor type II deficiency results in defects of yolk sac hematopoiesis and vasculogenesis. Dev Biol. 1996;179:297-302.

92. Larsson J, Goumans MJ, Sjöstrand LJ, van Rooijen MA, Ward D, Levéen $\mathrm{P}$, et al. Abnormal angiogenesis but intact hematopoietic potential in TGF-beta type I receptor-deficient mice. EMBO J. 2001;20:1663-73.

93. Wang J, Nagy A, Larsson J, Dudas M, Sucov HM, Kaartinen V. Defective ALK5 signaling in the neural crest leads to increased postmigratory neural crest cell apoptosis and severe outflow tract defects. BMC Dev Biol. 2006;6:51.

94. Choudhary B, Zhou J, Li P, Thomas S, Kaartinen V, Sucov HM. Absence of TGFbeta signaling in embryonic vascular smooth muscle leads to reduced lysyl oxidase expression, impaired elastogenesis, and aneurysm. Genesis. 2009;47:115-21.

95. Choudhary B, Ito Y, Makita T, Sasaki T, Chai Y, Sucov HM. Cardiovascular malformations with normal smooth muscle differentiation in neural crest-specific type II TGFbeta receptor (Tgfbr2) mutant mice. Dev Biol. 2006;289:420-9.

96. MacFarlane EG, Parker SJ, Shin JY, Kang BE, Ziegler SG, Creamer TJ, et al. Lineage-specific events underlie aortic root 
aneurysm pathogenesis in Loeys-Dietz syndrome. J Clin Invest. 2019;129:659-75.

97. Gallo EM, Loch DC, Habashi JP, Calderon JF, Chen Y, Bedja D, et al. Angiotensin II-dependent TGF- $\beta$ signaling contributes to Loeys-Dietz syndrome vascular pathogenesis. J Clin Invest. 2014;124:448-60.

98. Hu JH, Wei H, Jaffe M, Airhart N, Du L, Angelov SN, et al. Postnatal deletion of the type II transforming growth factor- $\beta$ receptor in smooth muscle cells causes severe aortopathy in mice. Arterioscler Thromb Vasc Biol. 2015;35:2647-56.

99. McLaughlin PJ, Chen Q, Horiguchi M, Starcher BC, Stanton JB, Broekelmann TJ, et al. Targeted disruption of fibulin-4 abolishes elastogenesis and causes perinatal lethality in mice. Mol Cell Biol. 2006;26:1700-9.

100. Huang J, Yamashiro Y, Papke CL, Ikeda Y, Lin Y, Patel M, et al. Angiotensin-converting enzyme-induced activation of local angiotensin signaling is required for ascending aortic aneurysms in fibulin-4-deficient mice. Sci Transl Med. 2013;5:183ra58 1-11.

101. Huang J, Davis EC, Chapman SL, Budatha M, Marmorstein LY, Word RA, et al. Fibulin-4 deficiency results in ascending aortic aneurysms: a potential link between abnormal smooth muscle cell phenotype and aneurysm progression. Circ Res. 2010;106:58392.

102. Yamashiro Y, Papke CL, Kim J, Ringuette LJ, Zhang QJ, Liu ZP, et al. Abnormal mechanosensing and cofilin activation promote the progression of ascending aortic aneurysms in mice. Sci Signal. 2015;8:ra105.

103. Hanada K, Vermeij M, Garinis GA, de Waard MC, Kunen MG, Myers L, et al. Perturbations of vascular homeostasis and aortic valve abnormalities in fibulin-4 deficient mice. Circ Res. 2007;100:738-46.

104. Ramnath NW, Hawinkels LJ, van Heijningen PM, te Riet L, Paauwe M, Vermeij M, et al. Fibulin-4 deficiency increases TGF- $\beta$ signalling in aortic smooth muscle cells due to elevated TGF- $\beta 2$ levels. Sci Rep. 2015;5:16872.

105. Igoucheva O, Alexeev V, Halabi CM, Adams SM, Stoilov I, Sasaki T, et al. Fibulin-4 E57K knock-in mice recapitulate cutaneous, vascular and skeletal defects of recessive cutis laxa $1 \mathrm{~B}$ with both elastic fiber and collagen fibril abnormalities. J Biol Chem. 2015;290:21443-59.

106. Habashi JP, Judge DP, Holm TM, Cohn RD, Loeys BL, Cooper TK, et al. Losartan, an AT1 antagonist, prevents aortic aneurysm in a mouse model of Marfan syndrome. Science. 2006;312:11721.

107. Lin F, Yang X. TGF- $\beta$ signaling in aortic aneurysm: another round of controversy. J Genet Genomics. 2010;37:583-91.

108. Maleszewski JJ, Miller DV, Lu J, Dietz HC, Halushka MK. Histopathologic findings in ascending aortas from individuals with Loeys-Dietz syndrome (LDS). Am J Surg Pathol. 2009;33: 194-201.

109. Loeys BL, Schwarze U, Holm T, Callewaert BL, Thomas GH, Pannu $\mathrm{H}$, et al. Aneurysm syndromes caused by mutations in the TGF-beta receptor. N Engl J Med. 2006;355:788-98.

110. Dietz HC. TGF-beta in the pathogenesis and prevention of disease: a matter of aneurysmic proportions. J Clin Invest. 2010;120: 403-7.

111. MacFarlane EG, Haupt J, Dietz HC, Shore EM. TGF- $\beta$ family signaling in connective tissue and skeletal diseases. Cold Spring Harb Perspect Biol. 2017;9.

112. Chen X, Lu H, Rateri DL, Cassis LA, Daugherty A. Conundrum of angiotensin II and TGF- $\beta$ interactions in aortic aneurysms. Curr Opin Pharmacol. 2013;13:180-5.

113. Jones A, Deb R, Torsney E, Howe F, Dunkley M, Gnaneswaran $\mathrm{Y}$, et al. Rosiglitazone reduces the development and rupture of experimental aortic aneurysms. Circulation. 2009;119:3125-32.
114. Cook JR, Clayton NP, Carta L, Galatioto J, Chiu E, Smaldone S, et al. Dimorphic effects of transforming growth factor- $\beta$ signaling during aortic aneurysm progression in mice suggest a combinatorial therapy for Marfan syndrome. Arterioscler Thromb Vasc Biol. 2015;35:911-7.

115. Li W, Li Q, Jiao Y, Qin L, Ali R, Zhou J, et al. Tgfbr2 disruption in postnatal smooth muscle impairs aortic wall homeostasis. J Clin Invest. 2014;124:755-67.

116. Langlois D, Hneino M, Bouazza L, Parlakian A, Sasaki T, Bricca $\mathrm{G}$, et al. Conditional inactivation of TGF- $\beta$ type II receptor in smooth muscle cells and epicardium causes lethal aortic and cardiac defects. Transgenic Res. 2010;19:1069-82.

117. Dickson MC, Martin JS, Cousins FM, Kulkarni AB, Karlsson S, Akhurst RJ. Defective haematopoiesis and vasculogenesis in transforming growth factor-beta 1 knock out mice. Development. 1995; 121:1845-54.

118. Goumans MJ, Mummery C. Functional analysis of the TGFbeta receptor/Smad pathway through gene ablation in mice. Int J Dev Biol. 2000;44:253-65.

119. Goumans MJ, Liu Z, ten Dijke P. TGF-beta signaling in vascular biology and dysfunction. Cell Res. 2009;19:116-27.

120. Chen X, Rateri DL, Howatt DA, Balakrishnan A, Moorleghen JJ, Cassis LA, et al. TGF- $\beta$ neutralization enhances AngII-induced aortic rupture and aneurysm in both thoracic and abdominal regions. PLoS One. 2016;11:e0153811

121. Gadson PF Jr, Dalton ML, Patterson E, Svoboda DD, Hutchinson L, Schram D, et al. Differential response of mesoderm- and neural crest-derived smooth muscle to TGF-beta1: regulation of c-myb and alpha1 (I) procollagen genes. Exp Cell Res. 1997;230:169-80.

122. Topouzis S, Majesky MW. Smooth muscle lineage diversity in the chick embryo. Two types of aortic smooth muscle cell differ in growth and receptor-mediated transcriptional responses to transforming growth factor-beta. Dev Biol. 1996;178:430-45.

123. Daugherty A, Rateri DL, Howatt DA, Charnigo R, Cassis LA. PD123319 augments angiotensin II-induced abdominal aortic aneurysms through an AT2 receptor-independent mechanism. PLoS One. 2013;8:e61849.

124. Daugherty A, Manning MW, Cassis LA. Angiotensin II promotes atherosclerotic lesions and aneurysms in apolipoprotein Edeficient mice. J Clin Invest. 2000;105:1605-12.

125. Rateri DL, Davis FM, Balakrishnan A, Howatt DA, Moorleghen JJ, O'Connor WN, et al. Angiotensin II induces region-specific medial disruption during evolution of ascending aortic aneurysms. Am J Pathol. 2014;184:2586-95.

126. Daugherty A, Rateri DL, Charo IF, Owens AP, Howatt DA, Cassis LA. Angiotensin II infusion promotes ascending aortic aneurysms: attenuation by CCR 2 deficiency in apoE-/- mice. Clin Sci (Lond). 2010;118:681-9.

127. Wang C, Chang Q, Sun X, Qian X, Liu P, Pei H, et al. Angiotensin II induces an increase in matrix metalloproteinase 2 expression in aortic smooth muscle cells of ascending thoracic aortic aneurysms through JNK, ERK1/2, and p38 MAPK activation. J Cardiovasc Pharmacol. 2015;66:285-93.

128. Nagashima H, Sakomura Y, Aoka Y, Uto K, Kameyama K, Ogawa $\mathrm{M}$, et al. Angiotensin II type 2 receptor mediates vascular smooth muscle cell apoptosis in cystic medial degeneration associated with Marfan's syndrome. Circulation. 2001;104:I282-7.

129. Groenink M, den Hartog AW, Franken R, Radonic T, de Waard $\mathrm{V}$, Timmermans $\mathrm{J}$, et al. Losartan reduces aortic dilatation rate in adults with Marfan syndrome: a randomized controlled trial. Eur Heart J. 2013;34:3491-500.

130. Mullen M, Jin XY, Child A, Stuart AG, Dodd M, Aragon-Martin JA, et al. Irbesartan in Marfan syndrome (AIMS): a double-blind, placebo-controlled randomised trial. Lancet. 2020;394:2263-70.

131. Galatioto J, Caescu CI, Hansen J, Cook JR, Miramontes I, Iyengar $\mathrm{R}$, et al. Cell type-specific contributions of the angiotensin II type 
1a receptor to aorta homeostasis and aneurysmal disease-brief report. Arterioscler Thromb Vasc Biol. 2018;38:588-91.

132. Rateri DL, Moorleghen JJ, Balakrishnan A, Owens AP 3rd, Howatt DA, Subramanian V, et al. Endothelial cell-specific deficiency of Ang II type 1a receptors attenuates Ang II-induced ascending aortic aneurysms in LDL receptor-/- mice. Circ Res. 2011;108:574-81.

133. Poduri A, Rateri DL, Howatt DA, Balakrishnan A, Moorleghen JJ, Cassis LA, et al. Fibroblast angiotensin II type 1a receptors contribute to angiotensin II-induced medial hyperplasia in the ascending aorta. Arterioscler Thromb Vasc Biol. 2015;35:1995-2002.

134. Milewicz DM, Ramirez F. Therapies for thoracic aortic aneurysms and acute aortic dissections. Arterioscler Thromb Vasc Biol. 2019;39:126-36.

135. Zhou Z, Peters AM, Wang S, Janda A, Chen J, Zhou P, et al. Reversal of aortic enlargement induced by increased biomechanical forces requires AT1R inhibition in conjunction with AT2R activation. Arterioscler Thromb Vasc Biol. 2019;39:459-66.

136. Te Riet L, van Deel ED, van Thiel BS, Moltzer E, van Vliet N, Ridwan Y, et al. AT1-receptor blockade, but not renin inhibition, reduces aneurysm growth and cardiac failure in fibulin- 4 mice. $\mathrm{J}$ Hypertens. 2016;34:654-65.

137. Verbrugghe P, Verhoeven J, Clijsters M, Vervoort D, Schepens J, Meuris B, et al. The effect of a nonpeptide angiotensin II type 2 receptor agonist, compound 21 , on aortic aneurysm growth in a mouse model of Marfan syndrome. J Cardiovasc Pharmacol. 2018;71:215-22.

138. Widdop RE, Jones ES, Hannan RE, Gaspari TA. Angiotensin AT2 receptors: cardiovascular hope or hype? Br J Pharmacol. 2003;140:809-24.

139. Lemarié CA, Schiffrin EL. The angiotensin II type 2 receptor in cardiovascular disease. J Renin-Angiotensin-Aldosterone Syst. 2010;11:19-31.

140. Subramanian V, Golledge J, Heywood EB, Bruemmer D, Daugherty A. Regulation of peroxisome proliferator-activated receptor- $\gamma$ by angiotensin II via transforming growth factor- $\beta 1$ activated p38 mitogen-activated protein kinase in aortic smooth muscle cells. Arterioscler Thromb Vasc Biol. 2012;32:397-405.

141. Gibbons GH, Pratt RE, Dzau VJ. Vascular smooth muscle cell hypertrophy vs. hyperplasia. Autocrine transforming growth factor-beta 1 expression determines growth response to angiotensin II. J Clin Invest. 1992;90:456-61.

142. Humphrey JD, Milewicz DM, Tellides G, Schwartz MA. Cell biology. Dysfunctional mechanosensing in aneurysms. Science. 2014;344:477-9.

143. Humphrey JD, Schwartz MA, Tellides G, Milewicz DM. Role of mechanotransduction in vascular biology: focus on thoracic aortic aneurysms and dissections. Circ Res. 2015;116:1448-61.

144. Guo DC, Pannu H, Tran-Fadulu V, Papke CL, Yu RK, Avidan N, et al. Mutations in smooth muscle alpha-actin (ACTA2) lead to thoracic aortic aneurysms and dissections. Nat Genet. 2007;39: 1488-93.

145. Gosgnach W, Challah M, Coulet F, Michel JB, Battle T. Shear stress induces angiotensin converting enzyme expression in cultured smooth muscle cells: possible involvement of bFGF. Cardiovasc Res. 2000;45:486-92.

146. Zou Y, Akazawa H, Qin Y, Sano M, Takano H, Minamino T, et al. Mechanical stress activates angiotensin II type 1 receptor without the involvement of angiotensin II. Nat Cell Biol. 2004;6:499-506.

147. Rakesh K, Yoo B, Kim IM, Salazar N, Kim KS, Rockman HA. Beta-Arrestin-biased agonism of the angiotensin receptor induced by mechanical stress. Sci Signal. 2010;3:ra46.

148. Matt P, Schoenhoff F, Habashi J, Holm T, Van Erp C, Loch D, et al. Circulating transforming growth factor-beta in Marfan syndrome. Circulation. 2009;120:526-32.
149. Franken R, Radonic T, den Hartog AW, Groenink M, Pals G, van Eijk M, et al. The revised role of TGF- $\beta$ in aortic aneurysms in Marfan syndrome. Neth Heart J. 2015;23:116-21.

150. Baron V, Adamson ED, Calogero A, Ragona G, Mercola D. The transcription factor Egr1 is a direct regulator of multiple tumor suppressors including TGFbeta1, PTEN, p53, and fibronectin. Cancer Gene Ther. 2006;13:115-24.

151. Rodríguez-Vita J, Sánchez-López E, Esteban V, Rupérez M, Egido J, Ruiz-Ortega M. Angiotensin II activates the Smad pathway in vascular smooth muscle cells by a transforming growth factor-beta-independent mechanism. Circulation. 2005;111: 2509-17.

152. Yang CQ, Li W, Li SQ, Li J, Li YW, Kong SX, et al. MCP-1 stimulates MMP-9 expression via ERK 1/2 and p38 MAPK signaling pathways in human aortic smooth muscle cells. Cell Physiol Biochem. 2014;34:266-76.

153. Rabkin SW. The role matrix metalloproteinases in the production of aortic aneurysm. Prog Mol Biol Transl Sci. 2017;147:239-65.

154. Nagasawa A, Yoshimura K, Suzuki R, Mikamo A, Yamashita O, Ikeda $\mathrm{Y}$, et al. Important role of the angiotensin II pathway in producing matrix metalloproteinase-9 in human thoracic aortic aneurysms. J Surg Res. 2013;183:472-7.

155. Krstic J, Santibanez JF. Transforming growth factor-beta and matrix metalloproteinases: functional interactions in tumor stromainfiltrating myeloid cells. ScientificWorldJournal. 2014;2014: 521754.

156. Huusko T, Salonurmi T, Taskinen P, Liinamaa J, Juvonen T, Pääkkö P, et al. Elevated messenger RNA expression and plasma protein levels of osteopontin and matrix metalloproteinase types 2 and 9 in patients with ascending aortic aneurysms. J Thorac Cardiovasc Surg. 2013;145:1117-23.

157. Chung AW, Yang HH, Radomski MW, van Breemen C. Longterm doxycycline is more effective than atenolol to prevent thoracic aortic aneurysm in marfan syndrome through the inhibition of matrix metalloproteinase-2 and -9. Circ Res. 2008;102:e73-85.

158. Yang HH, Kim JM, Chum E, van Breemen C, Chung AW. Effectiveness of combination of losartan potassium and doxycycline versus single-drug treatments in the secondary prevention of thoracic aortic aneurysm in Marfan syndrome. J Thorac Cardiovasc Surg. 2010;140:305-12.e2.

159. Xiong W, Knispel RA, Dietz HC, Ramirez F, Baxter BT. Doxycycline delays aneurysm rupture in a mouse model of Marfan syndrome. J Vasc Surg. 2008;47:166-72 discussion 72.

160. Shen M, Lee J, Basu R, Sakamuri SS, Wang X, Fan D, et al. Divergent roles of matrix metalloproteinase 2 in pathogenesis of thoracic aortic aneurysm. Arterioscler Thromb Vasc Biol. 2015;35:888-98.

161. Ruiz-Ortega M, Rodríguez-Vita J, Sanchez-Lopez E, Carvajal G, Egido J. TGF-beta signaling in vascular fibrosis. Cardiovasc Res. 2007;74:196-206.

162. Nollen GJ, Groenink M, Tijssen JG, van Der Wall EE, Mulder BJ. Aortic stiffness and diameter predict progressive aortic dilatation in patients with Marfan syndrome. Eur Heart J. 2004;25:1146-52.

163. Lavoie P, Robitaille G, Agharazii M, Ledbetter S, Lebel M, Larivière R. Neutralization of transforming growth factor-beta attenuates hypertension and prevents renal injury in uremic rats. $\mathrm{J}$ Hypertens. 2005;23:1895-903.

164. Lim DS, Lutucuta S, Bachireddy P, Youker K, Evans A, Entman $\mathrm{M}$, et al. Angiotensin II blockade reverses myocardial fibrosis in a transgenic mouse model of human hypertrophic cardiomyopathy. Circulation. 2001;103:789-91.

165. Brooke BS, Habashi JP, Judge DP, Patel N, Loeys B, Dietz HC 3rd. Angiotensin II blockade and aortic-root dilation in Marfan's syndrome. N Engl J Med. 2008;358:2787-95.

166. Chiu HH, Wu MH, Wang JK, Lu CW, Chiu SN, Chen CA, et al. Losartan added to $\beta$-blockade therapy for aortic root dilation in 
Marfan syndrome: a randomized, open-label pilot study. Mayo Clin Proc. 2013;88:271-6.

167. Lacro RV, Dietz HC, Sleeper LA, Yetman AT, Bradley TJ, Colan $\mathrm{SD}$, et al. Atenolol versus losartan in children and young adults with Marfan's syndrome. N Engl J Med. 2014;371:2061-71.

168. Milleron O, Arnoult F, Ropers J, Aegerter P, Detaint D, Delorme G, et al. Marfan Sartan: a randomized, double-blind, placebocontrolled trial. Eur Heart J. 2015;36:2160-6.

169. Forteza A, Evangelista A, Sánchez V, Teixidó-Turà G, Sanz P, Gutiérrez L, et al. Efficacy of losartan vs. atenolol for the prevention of aortic dilation in Marfan syndrome: a randomized clinical trial. Eur Heart J. 2016;37:978-85.

170. Muiño-Mosquera L, De Nobele S, Devos D, Campens L, De Paepe A, De Backer J. Efficacy of losartan as add-on therapy to prevent aortic growth and ventricular dysfunction in patients with Marfan syndrome: a randomized, double-blind clinical trial. Acta Cardiol. 2017;72:616-24.

171. Di Toro A, Klersy C, Giuliani L, Serio A, Disabella E, Grasso M, et al. 6128Losartan vs Nebivolol vs the association of both on the progression of aortic root dilation in genotyped Marfan syndrome: 48 months open label randomized controlled phase III trial. Eur Heart J. 2019;40.

172. Mueller GC, Stierle L, Stark V, Steiner K, von Kodolitsch Y, Weil $\mathrm{J}$, et al. Retrospective analysis of the effect of angiotensin II receptor blocker versus $\beta$-blocker on aortic root growth in paediatric patients with Marfan syndrome. Heart. 2014;100:214-8.

173. Shores J, Berger KR, Murphy EA, Pyeritz RE. Progression of aortic dilatation and the benefit of long-term beta-adrenergic blockade in Marfan's syndrome. N Engl J Med. 1994;330:1335-41.

174. Chun AS, Elefteriades JA, Mukherjee SK. Do $\beta$-blockers really work for prevention of aortic aneurysms?: time for reassessment. Aorta (Stamford). 2013;1:45-51.

175. Koo HK, Lawrence KA, Musini VM. Beta-blockers for preventing aortic dissection in Marfan syndrome. Cochrane Database Syst Rev. 2017;11:Cd011103.

176. Lacro RV, Dietz HC, Mahony L. Atenolol versus losartan in Marfan's syndrome. N Engl J Med. 2015;372:980-1.

177. Hofmann Bowman MA, Eagle KA, Milewicz DM. Update on clinical trials of losartan with and without $\beta$-blockers to block aneurysm growth in patients with Marfan syndrome: a review. JAMA Cardiol. 2019;4:702-7.

178. Teixido-Tura G, Forteza A, Rodríguez-Palomares J, González Mirelis J, Gutiérrez L, Sánchez V, et al. Losartan versus atenolol for prevention of aortic dilation in patients with Marfan syndrome. J Am Coll Cardiol. 2018;72:1613-8.

179. van Andel MM, Indrakusuma R, Jalalzadeh H, Balm R, Timmermans J, Scholte AJ, et al. Long-term clinical outcomes of losartan in patients with Marfan syndrome: follow-up of the multicentre randomized controlled COMPARE trial. Eur Heart J. 2020 .

180. Al-Abcha A, Saleh Y, Mujer M, Boumegouas M, Herzallah K, Charles L, et al. Meta-analysis examining the usefulness of angiotensin receptor blockers for the prevention of aortic root dilation in patients with the Marfan syndrome. Am J Cardiol. 2020;128:101-6.

181. Abraham HM, White CM, White WB. The comparative efficacy and safety of the angiotensin receptor blockers in the management of hypertension and other cardiovascular diseases. Drug Saf. 2015;38:33-54.

182. Border WA, Noble NA. Interactions of transforming growth factor-beta and angiotensin II in renal fibrosis. Hypertension. 1998;31:181-8.

183. Krishna SM, Seto SW, Jose R, Li J, Moxon J, Clancy P, et al. High serum thrombospondin-1 concentration is associated with slower abdominal aortic aneurysm growth and deficiency of thrombospondin-1 promotes angiotensin II induced aortic aneurysm in mice. Clin Sci (Lond). 2017;131:1261-81.

184. Collod-Béroud G, Le Bourdelles S, Ades L, Ala-Kokko L, Booms $\mathrm{P}$, Boxer M, et al. Update of the UMD-FBN1 mutation database and creation of an FBN1 polymorphism database. Hum Mutat. 2003;22:199-208

185. Dietz H. Marfan syndrome. 2001 Apr 18 [Updated 2017 Oct 12]. In: Adam MP AH, Pagon RA, et al., editors. GeneReviews ${ }^{\circledR}$ [Internet]. Seattle (WA): University of Washington, Seattle; 1993-2020. Retrieved from https://www.ncbi.nlm.nih.gov/books/ NBK1335/?report=classic. Accessed 31 Aug 2020.

186. Faivre L, Collod-Beroud G, Loeys BL, Child A, Binquet C, Gautier E, et al. Effect of mutation type and location on clinical outcome in 1,013 probands with Marfan syndrome or related phenotypes and FBN1 mutations: an international study. Am J Hum Genet. 2007;81:454-66.

187. Franken R, Teixido-Tura G, Brion M, Forteza A, RodriguezPalomares J, Gutierrez L, et al. Relationship between fibrillin-1 genotype and severity of cardiovascular involvement in Marfan syndrome. Heart. 2017;103:1795-9.

188. Franken R, den Hartog AW, Radonic T, Micha D, Maugeri A, van Dijk FS, et al. Beneficial outcome of losartan therapy depends on type of FBN1 mutation in Marfan syndrome. Circ Cardiovasc Genet. 2015;8:383-8.

189. Pitcher A, Emberson J, Lacro RV, Sleeper LA, Stylianou M, Mahony L, et al. Design and rationale of a prospective, collaborative meta-analysis of all randomized controlled trials of angiotensin receptor antagonists in Marfan syndrome, based on individual patient data: a report from the Marfan Treatment Trialists' Collaboration. Am Heart J. 2015;169:605-12.

190. Sullivan RJ, Infante JR, Janku F, Wong DJL, Sosman JA, Keedy $\mathrm{V}$, et al. First-in-class ERK1/2 inhibitor ulixertinib (BVD-523) in patients with MAPK mutant advanced solid tumors: results of a phase I dose-escalation and expansion study. Cancer Discov. 2018;8:184-95.

191. Granata A, Serrano F, Bernard WG, McNamara M, Low L, Sastry $\mathrm{P}$, et al. An iPSC-derived vascular model of Marfan syndrome identifies key mediators of smooth muscle cell death. Nat Genet. 2017;49:97-109.

192. van der Pluijm I, Burger J, van Heijningen PM, A IJ, van Vliet N, Milanese $\mathrm{C}$, et al. Decreased mitochondrial respiration in aneurysmal aortas of Fibulin-4 mutant mice is linked to PGC1A regulation. Cardiovasc Res. 2018;114:1776-93.

Publisher's Note Springer Nature remains neutral with regard to jurisdictional claims in published maps and institutional affiliations. 